\title{
Sensitivity of potential evapotranspiration to changes in climate variables for different Australian climatic zones
}

\author{
Danlu Guo, Seth Westra, and Holger R. Maier \\ School of Civil, Environmental and Mining Engineering, University of Adelaide, North Terrace, \\ Adelaide, SA 5005, Australia \\ Correspondence to: Danlu Guo (danlu.guo@adelaide.edu.au)
}

Received: 26 August 2016 - Discussion started: 19 September 2016

Revised: 19 March 2017 - Accepted: 20 March 2017 - Published: 19 April 2017

\begin{abstract}
Assessing the factors that have an impact on potential evapotranspiration (PET) sensitivity to changes in different climate variables is critical to understanding the possible implications of climatic changes on the catchment water balance. Using a global sensitivity analysis, this study assessed the implications of baseline climate conditions on the sensitivity of PET to a large range of plausible changes in temperature $(T)$, relative humidity $(\mathrm{RH})$, solar radiation $\left(R_{\mathrm{S}}\right)$ and wind speed $\left(u_{z}\right)$. The analysis was conducted at 30 Australian locations representing different climatic zones, using the Penman-Monteith and Priestley-Taylor PET models. Results from both models suggest that the baseline climate can have a substantial impact on overall PET sensitivity. In particular, approximately 2-fold greater changes in PET were observed in cool-climate energy-limited locations compared to other locations in Australia, indicating the potential for elevated water loss as a result of increasing actual evapotranspiration (AET) in these locations. The two PET models consistently indicated temperature to be the most important variable for PET, but showed large differences in the relative importance of the remaining climate variables. In particular for the Penman-Monteith model, wind and relative humidity were the second-most important variables for dry and humid catchments, respectively, whereas for the PriestleyTaylor model solar radiation was the second-most important variable, with the greatest influence in warmer catchments. This information can be useful to inform the selection of suitable PET models to estimate future PET for different climate conditions, providing evidence on both the structural plausibility and input uncertainty for the alternative models.
\end{abstract}

\section{Introduction}

Assessing changes to evapotranspiration (ET) is critical in understanding the impacts of anthropogenic climate change on the catchment water balance. ET represents the dominant loss of water from catchments worldwide, with about $62 \%$ of global land-surface precipitation accounted for by ET (Dingman, 2015), and ET exceeding runoff in over $77 \%$ of the global land surface (Harrigan and Berghuijis, 2016). ET is affected by climate change through a cascade of processes that begins with the increasing concentration of greenhouse gases, followed by their attendant impacts on largescale circulation and changes to the global distribution of energy and moisture. These large-scale processes lead to localscale changes in the atmosphere, which in turn influence the catchment water balance through a set of terrestrial hydrological processes by which precipitation is converted into actual ET (AET), runoff and groundwater recharge (Oudin et al., 2005). Other factors that can potentially affect ET under a changing climate include changing land cover patterns (e.g., Liu et al., 2008), and the $\mathrm{CO}_{2}$ fertilization effects that can limit the rate of plant transpiration under elevated levels of $\mathrm{CO}_{2}$ (e.g., Prudhomme et al., 2014; Milly and Dunne, 2016).

Climate impact studies that investigate the influence of climate forcings on the catchment water balance are usually based on projections of future climate represented by climate variables such as temperature and solar radiation from general circulation models (GCMs), which are converted into potential ET (PET) using one or several PET models. The PET projections are combined with GCM projections of precipitation $(P)$, which together can be used to directly estimate the water deficit (Taylor et al., 2013; Chang et al., 
2016). Alternatively, rainfall-runoff models can be used to translate the changes in $P$ and PET into changes in runoff (e.g., Akhtar et al., 2008; Chiew et al., 2009; Koedyk and Kingston, 2016), as well as associated information such as the impact on catchment streamflow (Wilby et al., 2006), water supply security (Paton et al., 2013, 2014) and flood risk (Bell et al., 2016). Therefore, to quantify the specific impact of changes in ET on the water balance, a good understanding of the sensitivity of PET to potential changes in its key influencing climatic variables is required (Goyal, 2004; Tabari and Hosseinzadeh Talaee, 2014). This is particularly relevant given the recent focus on "scenario-neutral" (or "bottomup") approaches to climate impact assessment (Brown et al., 2012; Prudhomme et al., 2010; Culley et al., 2016), which require the sensitivity of a given system to potential changes in climate forcings to be estimated (Prudhomme et al., 2013a, b; Steinschneider and Brown, 2013; Kay et al., 2014; Guo et al., 2016a).

Furthermore, the sensitivity of PET can provide critical evidence in relation to identifying models that are most appropriate for PET estimation under climate change conditions, which is particularly relevant to the ongoing debate on the potential trade-off between model complexity and reliability. Complex models such as the Penman-Monteith model are often recommended for their ability to better represent the physical processes that affect PET (McVicar et al., 2012; Donohue et al., 2010; Barella-Ortiz et al., 2013). For example, the Penman-Monteith model can account for the effects of wind, and thus can help explain at least part of the observed decreases in pan-evaporation with increases in temperature in many locations globally - the "evaporation paradox" - due to the observed decreases in wind speed (Roderick et al., 2007; McVicar et al., 2008; Lu et al., 2016). However, simpler empirical models may also be preferable under some conditions, as they require a smaller number of input climate variables, which might be able to be projected with greater confidence with GCMs, and thus leading to greater confidence in the corresponding PET estimates (Kay and Davies, 2008; Ekström et al., 2007; Ravazzani et al., 2014). For example, there is reasonable confidence in projections of temperature and relative humidity in Australia for a given emission scenario, but less confidence in projections of wind due to sub-grid effects of orography and other land-surface features (Flato et al., 2013; CSIRO and Bureau of Meteorology, 2015). In these situations, models such as the PriestleyTaylor model that do not depend on wind may produce more reliable estimates of PET compared to the more complex Penman-Monteith model. Thus, the choice of climate variables to include in climate impact assessments must be informed both by the relative importance of each variable on projections of PET (e.g., Tabari and Hosseinzadeh Talaee, 2014), and the likely confidence in the projections of each variable (e.g., Flato et al., 2013; Johnson and Sharma, 2009).

Sensitivity analysis methods have been employed in a number of recent studies to assess the overall sensitivity of
PET estimated by the Penman-Monteith model to potential changes in climate, as well as to better understand the relative importance of different climate variables on overall PET sensitivity. For example, Goyal (2004) found that PET was most sensitive to perturbations in temperature, followed by solar radiation, wind speed and vapor pressure, at a single study site in an arid region in India. Tabari and Hosseinzadeh Talaee (2014) also looked at the sensitivity of PET to perturbations of historical climate data from eight meteorological stations representing four climate types in Iran, and concluded that the importance of wind speed and air temperature was lower while that of sunshine hours was higher for a humid location compared to an arid location. Gong et al. (2006) found that the differences in PET sensitivity across the upper, middle and lower regions of the Changiiang (Yangtze) basin in China were largely due to contrasting baseline wind speed patterns. However, most of these PET sensitivity analysis studies focused on a limited number of study sites and/or climatic zones; therefore, the specific causes for varying PET sensitivity at different locations, such as the roles of climatic and hydrological conditions, remain unclear. Consequently, it is difficult to extrapolate our existing knowledge of PET sensitivity and the relative importance of each climate variable to new locations, which is essential for assessing the water balance at regional scales.

To address the shortcomings of existing studies outlined above, this study aims to gain an understanding of (i) the sensitivity of PET estimates to changes in the key climatic variables that influence PET, and how these sensitivity estimates are affected by varying baseline hydrologic and climatic conditions at different locations; and (ii) the relative importance of these climatic variables for PET, and how this changes with the baseline hydrologic and climatic conditions at different locations. These aims were achieved by analyzing the responses of PET to perturbations in four of its driving climatic variables, namely temperature $(T)$, relative humidity $(\mathrm{RH})$, solar radiation $\left(R_{\mathrm{S}}\right)$ and wind speed $\left(u_{z}\right)$, at 30 study sites across Australia representing a range of climate zones. Both the Penman-Monteith and Priestley-Taylor models were used, as they represent different conceptualizations of the PET-related processes, with both models being widely used for climate impact assessments (Felix et al., 2013; Arnell, 1999; Gosling et al., 2011; Kay et al., 2009; Prudhomme and Williamson, 2013; Donohue et al., 2009). It is worth noting that the potential changes in one climate variable can be amplified or offset by changes in another variable (for examples see the discussions of "evaporation paradox" in Lu et al., 2016; Roderick and Farquhar, 2002), which can affect the relative importance of each variable. To account for this effect, a global sensitivity analysis method was used, with similar methods being applied to account for the impact of joint variations in the input variables on the output from a variety of environmental models, ranging from conceptual rainfall-runoff models (e.g., Tang et al., 2007a, c) to complex models that consider a number of surface-groundwater 


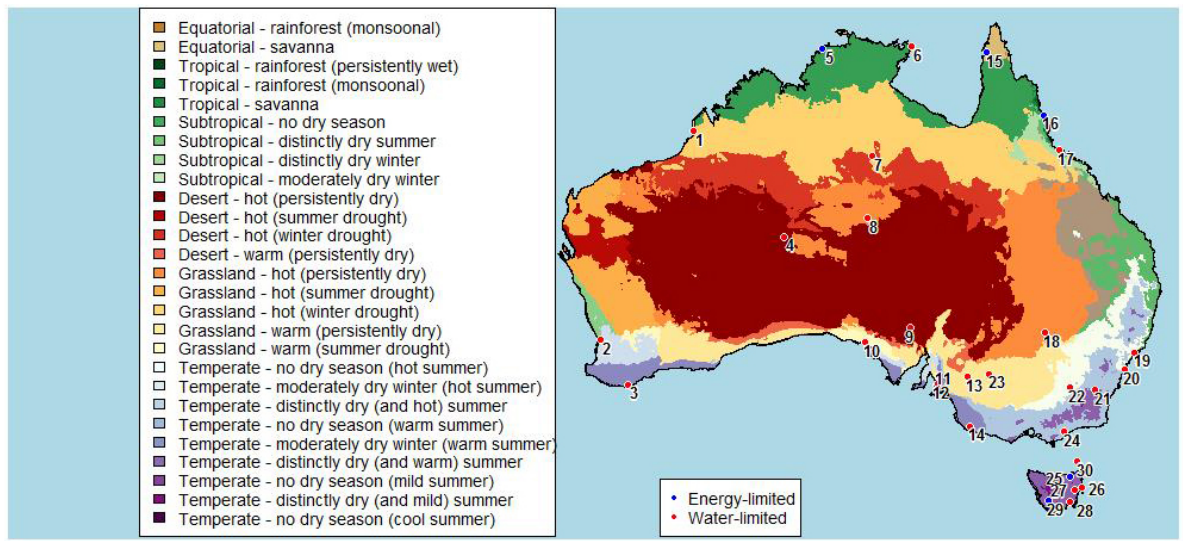

Figure 1. Locations of 30 Australian weather stations selected for analysis (see Table 1 for the full names of these weather stations), with reference to their corresponding climate classes derived following the modified Köppen classification (reproduced with data from Stern et al., 2000).

processes (e.g., Guillevic et al., 2002; van Griensven et al., 2006; Nossent et al., 2011). The results of the global sensitivity analysis in this study were presented in terms of both the range of potential changes in PET and relative sensitivity indices of each climate variable for PET, which were then used to elucidate the specific roles of varying baseline hydroclimatic conditions on influencing these sensitivity measures.

The subsequent sections of this paper are structured as follows. Section 2 introduces the data obtained from the 30 study sites required for the global sensitivity analysis. Section 3 describes the approach to the global sensitivity analysis of PET. Section 4 presents and discusses two sets of results that address the two study aims, respectively, (i) the range of estimated changes in PET in response to potential changes in temperature, solar radiation, humidity and wind, and how this changes with location, and (ii) the relative importance of the four climate variables for estimating PET, and how this changes with location. The study is summarized and concluded in Sect. 5.

\section{Data}

To represent contrasting hydro-climatic conditions for assessing PET sensitivity, we selected case study locations within different Köppen classes in Australia. The original Koöppen climate classification (Köppen et al., 1930; Köppen, 1931) provides a useful categorization of hydro-climatic conditions at specific locations, which is based on the longterm average levels and seasonal patterns of climatic and hydrologic variables, including temperature, relative humidity and rainfall. A "modified Köppen classification" system has been adapted for Australia (as in Stern et al., 2000) and is now widely used in climatic and hydrologic studies to identify and categorize case study locations (e.g., Johnson and Sharma, 2009; Rustomji et al., 2009; Li et al., 2014; Guo et al., 2017).
As mentioned in the Introduction, both the PenmanMonteith and the Priestley-Taylor models were used to estimate PET for the global sensitivity analyses. The estimation of PET with these models relies on temperature, relative humidity, solar radiation and (for the Penman-Monteith model only) wind speed. In addition, the rainfall data were also obtained to assess the aridity of the different locations. We limited the selection of study sites to those with 10 or more years of continuous climate data with no more than $5 \%$ missing records over the study period. This led to a final selection of 30 weather stations (Fig. 1), with a consistent data period from 1 January 1995 to 31 December 2004. The data obtained at each site are detailed as below:

- Daily maximum and minimum temperature $\left(T\right.$ in $\left.{ }^{\circ} \mathrm{C}\right)$, maximum and minimum relative humidity (RH in \%) and wind speed $\left(u_{z}\right.$ in $\left.\mathrm{m} \mathrm{s}^{-1}\right)$ : data for each of these variables were obtained directly from each weather station.

- Daily solar radiation $\left(R_{\mathrm{S}}\right.$ in $\mathrm{MJ} \mathrm{m}^{-2}$ day $\left.^{-1}\right)$ : daily solar radiation was calculated from daily sunshine hour data ( $n$ in h) obtained from each weather station, using the Ångström-Prescott equation as in McMahon et al. (2013).

- Daily rainfall $\left(\mathrm{mm} \mathrm{day}^{-1}\right)$ : daily rainfall data were obtained from a rain gauge at each weather station.

Table 1 shows the average values of the four PET-related climate variables, as well as the rainfall within the study period, at each of the 30 sites. As can be seen, there are large differences in the average values of each variable, highlighting large differences in the climatic conditions across the 30 sites. In addition, a quantity particularly relevant to ET processes is the long-term-averaged ratio of PET to precipitation (PET / $P$ ), which describes whether a location is waterlimited (PET $/ P>1$ ) or energy-limited (PET $/ P<1)(\mathrm{Ger}-$ 
Table 1. Names, locations and average climate conditions of the 30 weather stations over the study period (1995-2004).

\begin{tabular}{|c|c|c|c|c|c|c|c|c|c|c|c|c|}
\hline No. & $\begin{array}{l}\text { Study site } \\
\text { name }\end{array}$ & $\begin{array}{c}\text { Köppen } \\
\text { class }^{\mathrm{a}}\end{array}$ & $\begin{array}{l}\text { Lat } \\
\left({ }^{\circ} \mathrm{S}\right)\end{array}$ & $\begin{array}{l}\text { Long } \\
\left({ }^{\circ} \mathrm{E}\right)\end{array}$ & $\begin{array}{r}\text { Elev } \\
(\mathrm{m})\end{array}$ & $\begin{array}{c}T^{\mathrm{b}} \\
\left({ }^{\circ} \mathrm{C}\right)\end{array}$ & $\begin{array}{l}\mathrm{RH}^{2} \\
(\%)\end{array}$ & $\begin{array}{c}R_{\mathrm{S}}^{\mathrm{b}} \\
\left(\mathrm{MJ} \mathrm{m}^{-2}\right. \\
\left.\mathrm{day}^{-1}\right)\end{array}$ & $\begin{array}{c}u_{z}^{\mathrm{b}} \\
\left(\mathrm{ms}^{-1}\right)\end{array}$ & $\begin{array}{r}\text { Annual } \\
P^{\mathrm{b}}(\mathrm{mm})\end{array}$ & $\begin{array}{r}\text { Annual } \\
\text { PET }^{\mathrm{b}} \\
(\mathrm{mm})\end{array}$ & $\begin{array}{c}\text { Annual } \\
\text { PET / } P^{\mathrm{b}}\end{array}$ \\
\hline 1 & Broome airport & 13 & -17.95 & 122.2 & 7.4 & 26.37 & 65.15 & 21.55 & 3.684 & 865 & 2003 & 2.317 \\
\hline 2 & Perth & 8 & -31.93 & 116.0 & 15.4 & 18.54 & 61.72 & 18.95 & 4.519 & 721 & 1751 & 2.429 \\
\hline 3 & Albany & 4 & -34.94 & 117.8 & 68 & 15.08 & 73.59 & 15.20 & 4.382 & 752 & 1126 & 1.498 \\
\hline 4 & Giles & 24 & -25.03 & 128.3 & 598 & 22.70 & 38.40 & 20.29 & 4.380 & 394 & 2344 & 5.947 \\
\hline 5 & Darwin & 35 & -12.42 & 130.9 & 30.4 & 27.42 & 69.27 & 20.33 & 3.393 & 1976 & 1864 & 0.944 \\
\hline 6 & Gove & 35 & -12.27 & 136.8 & 51.6 & 26.29 & 75.93 & 19.45 & 3.500 & 1607 & 1660 & 1.033 \\
\hline 7 & Tennant Creek & 13 & -19.64 & 134.2 & 375.7 & 25.73 & 37.21 & 21.64 & 4.759 & 539 & 2634 & 4.886 \\
\hline 8 & Alice Springs & 15 & -23.80 & 133.9 & 546 & 21.18 & 44.53 & 20.79 & 2.352 & 331 & 1822 & 5.503 \\
\hline 9 & Woomera & 24 & -31.16 & 136.8 & 166.6 & 19.41 & 46.57 & 19.40 & 5.057 & 151 & 2153 & 14.24 \\
\hline 10 & Ceduna & 11 & -32.13 & 133.7 & 15.3 & 16.92 & 62.04 & 18.20 & 5.450 & 266 & 1723 & 6.478 \\
\hline 11 & Adelaide airport & 12 & -34.95 & 138.5 & 2 & 16.37 & 63.04 & 16.91 & 4.213 & 454 & 1410 & 3.107 \\
\hline 12 & Adelaide (kent town) & 12 & -34.92 & 138.6 & 48 & 16.95 & 61.20 & 16.88 & 3.161 & 569 & 1372 & 2.409 \\
\hline 13 & Loxton & 12 & -34.44 & 140.6 & 30.1 & 16.50 & 59.41 & 17.59 & 3.250 & 255 & 1490 & 5.847 \\
\hline 14 & Mount Gambier & 4 & -37.75 & 140.8 & 63 & 13.45 & 72.77 & 14.91 & 4.460 & 731 & 1116 & 1.526 \\
\hline 15 & Weipa & 41 & -12.68 & 141.9 & 18 & 26.87 & 72.21 & 19.31 & 3.271 & 2154 & 1782 & 0.827 \\
\hline 16 & Cairns & 36 & -16.87 & 145.7 & 3 & 24.80 & 73.00 & 18.98 & 4.352 & 1985 & 1678 & 0.845 \\
\hline 17 & Townsville & 35 & -19.25 & 146.8 & 4.3 & 24.53 & 69.45 & 20.27 & 4.304 & 1099 & 1802 & 1.641 \\
\hline 18 & Cobar & 15 & -31.48 & 145.8 & 260 & 19.08 & 50.64 & 19.05 & 2.458 & 398 & 1565 & 3.936 \\
\hline 19 & Williamtown & 9 & -32.79 & 151.8 & 9 & 17.84 & 70.57 & 16.07 & 3.927 & 1145 & 1309 & 1.143 \\
\hline 20 & Sydney & 9 & -33.94 & 151.2 & 6 & 18.19 & 67.69 & 15.97 & 5.311 & 1017 & 1393 & 1.369 \\
\hline 21 & Canberra & 6 & -35.30 & 149.2 & 578.4 & 13.36 & 65.82 & 16.86 & 3.302 & 590 & 1226 & 2.078 \\
\hline 22 & Wagga Wagga & 9 & -35.16 & 147.5 & 212 & 15.77 & 61.78 & 17.48 & 3.288 & 552 & 1436 & 2.602 \\
\hline 23 & Mildura & 12 & -34.24 & 142.1 & 50 & 17.11 & 55.62 & 18.24 & 3.604 & 246 & 1645 & 6.681 \\
\hline 24 & East sale & 6 & -38.12 & 147.1 & 4.6 & 13.77 & 72.32 & 14.92 & 4.062 & 529 & 1093 & 2.067 \\
\hline 25 & Scottsdale & 3 & -41.17 & 147.5 & 197.5 & 13.19 & 70.55 & 14.23 & 2.921 & 931 & 912 & 0.980 \\
\hline 26 & Bicheno & 3 & -41.87 & 148.3 & 11 & 14.69 & 66.68 & 13.69 & 3.319 & 690 & 966 & 1.401 \\
\hline 27 & Lake Leake & 3 & -42.01 & 147.8 & 575 & 9.96 & 75.40 & 13.44 & 3.358 & 732 & 774 & 1.056 \\
\hline 28 & Hobart & 3 & -42.83 & 147.5 & 4 & 12.77 & 65.67 & 14.04 & 4.367 & 483 & 1097 & 2.273 \\
\hline 29 & Strathgordon village & 3 & -42.77 & 146.0 & 322 & 10.70 & 77.95 & 11.65 & 2.473 & 2626 & 699 & 0.266 \\
\hline 30 & Flinders Island & 3 & -40.09 & 148.0 & 9 & 13.54 & 73.59 & 14.34 & 6.399 & 654 & 1064 & 1.626 \\
\hline
\end{tabular}

Note: ${ }^{\text {a }}$ The Köppen classes are presented with their corresponding identifiers from Stern et al. (2000), as (3) temperate - no dry season (mild summer); (4) temperate - distinctly dry (and warm) summer; (6) temperate - no dry season (warm summer); (8) temperate - moderately dry winter (hot summer); (9) temperate - no dry season (hot summer); (11) grassland - warm (summer drought); (12) grassland - warm (persistently dry); (13) grassland - hot (winter drought); (15) grassland - hot (persistently dry); (24) desert - hot (persistently dry); (35) tropical savanna; (36) tropical - rainforest (monsoonal); (41) equatorial - savanna. ${ }^{\mathrm{b}} T$ is temperature, RH is relative humidity, $R_{\mathrm{S}}$ is incoming solar radiation, $u_{z}$ is wind speed, $P$ is rainfall, $\mathrm{PET}$ is potential evapotranspiration calculated using the Penman-Monteith model.

rits et al., 2009; McVicar et al., 2010). This ratio was estimated for each site and is also shown in Table 1 (with the point color in Fig. 1 indicating whether the location is waterlimited or energy-limited). The range of PET / $P$ values indicates substantial variations in the water availability conditions at different study sites. Note that these ratios were based on the estimates of PET from the Penman-Monteith model. Although the use of Priestley-Taylor model resulted in different PET estimates at each site, the categorization of waterand energy-limited catchments was generally consistent with those from Penman-Monteith, with different categories only shown at 4 out of the 30 study sites (sites 6, 19, 20 and 27).

\section{Method}

\subsection{Overview}

A schematic of the approach followed in study is shown in Fig. 2. As a required model input for the global sensitivity analysis, a large number of representative samples were first obtained for the four climate variables that influence PET ( $T$, $\mathrm{RH}, R_{\mathrm{S}}$ and $u_{z}$ ) at each study site, by perturbing the corresponding historical climate data (Sect. 3.2). The outputs of the global sensitivity analysis (i.e., the responses of PET) were estimated with the Penman-Monteith and PriestleyTaylor models (Sect. 3.3). To understand the PET sensitivity and the relative importance of the four climate variables in influencing PET and how these change with location, a global sensitivity analysis was conducted with the responses of PET to the climate perturbations (Sect. 3.4). This proceeded in two parts: 


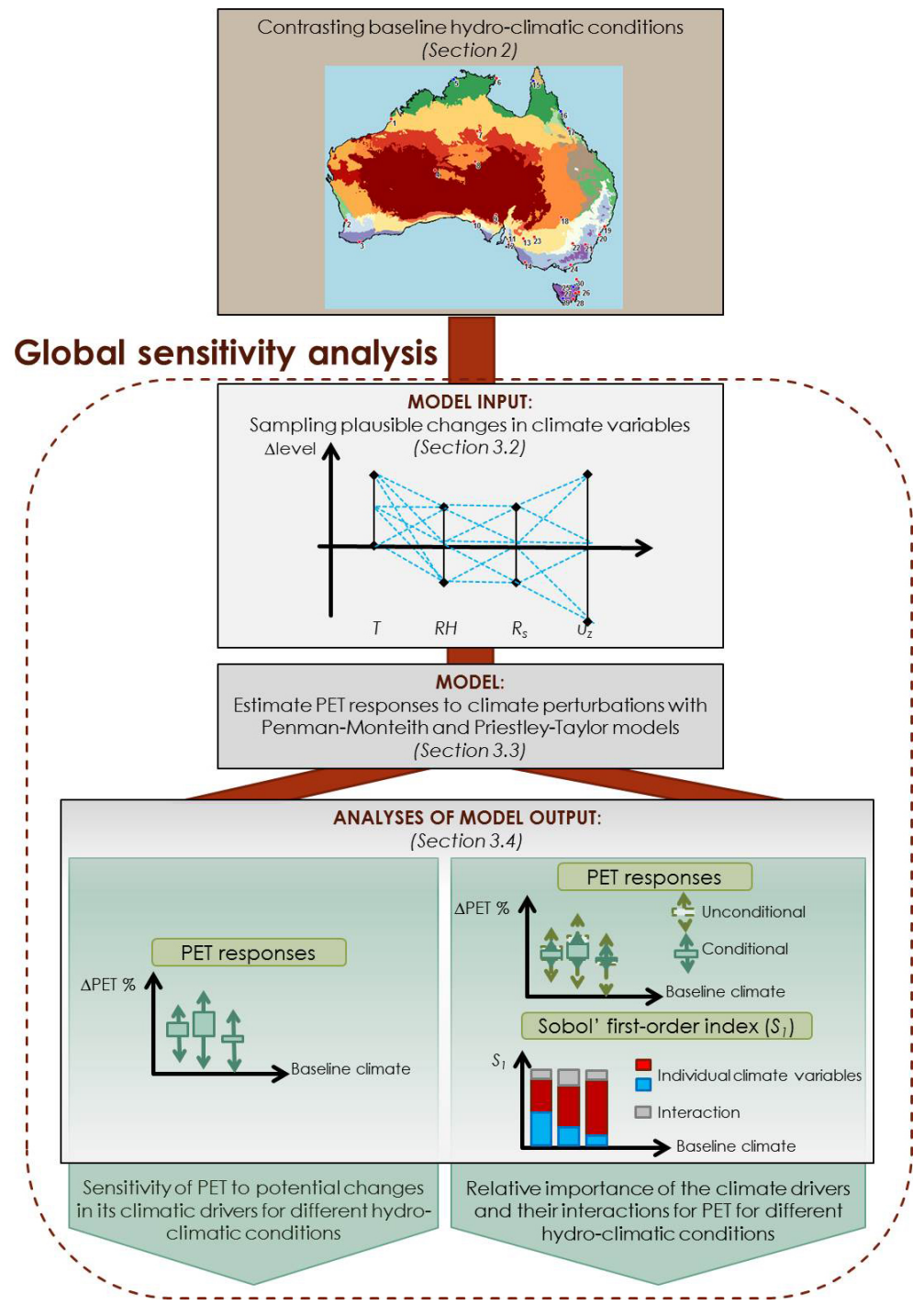

Figure 2. Schematic of the method used in this study.

1. To assess the sensitivity of PET to the climate variables, the range of percentage changes in PET in response to all the climate perturbations was estimated relative to the baseline PET at each location. To observe the impact of varying baseline hydro-climatic conditions, the ranges obtained from each PET model were also plotted against the baseline levels of each climate variable for all study sites.

2. To assess the relative importance of each climate variable, the range of percentage responses in PET to all climate perturbations in (1) was first compared to the conditional range of percentage responses in PET with holding each variable constant. This comparison enables an assessment of the relative impact of each variable on the potential responses of PET. An alternative presentation of the individual and interaction effects of the climate variables was achieved using the Sobol' method (Sobol' et al., 2007). Here, the total variance of PET was estimated based on different samples drawn from the perturbed ranges of each climate variable, and then partitioned into the individual contribution from each climate variable and their interactions (see Appendix A1 for details). The Sobol' first-order sensitivity indices were estimated and plotted against the baseline levels of each climate variable for all study sites to explore the role of varying baseline hydro-climatic conditions on the relative importance of each climatic variable for PET. 


\subsection{Representing plausible changes in the climatic variables}

As part of the global sensitivity analysis, a large number of representative combinations of the changes in the four climate variables $\left(T, \mathrm{RH}, R_{\mathrm{S}}\right.$ and $\left.u_{z}\right)$ were obtained. The upper and lower bounds for perturbing each climate variable were determined based on the uncertainty bounds of projections for 2100 for Australia (Stocker et al., 2013). The selected bounds are given in Table 2, which are all slightly wider than those presented in Stocker et al. (2013) to encompass a comprehensive range of plausible future climate change scenarios. Within these bounds, samples were drawn for different combinations of changes in each climatic variable. Latin hypercube sampling (LHS) was used for this purpose due to its effectiveness in covering multi-dimensional input spaces (Osidele and Beck, 2001; Sieber and Uhlenbrook, 2005; Tang et al., 2007b).

According to Nossent et al. (2011) and Zhang et al. (2015), the sample size was selected to ensure the convergence of the first- and total-order Sobol' sensitivity indices, which occurs when the width of the $95 \%$ confidence intervals from 1000 -fold bootstrap re-sampling of the each index is below $10 \%$ of the corresponding mean obtained from bootstrapping. Specifically, we generated different sizes of LHS samples of climate perturbations with the historical climate data from one study site, from which the PET responses were estimated using the Penman-Monteith model. The 1000-fold bootstrap estimates for the Sobol' first- and total-order sensitivity indices for each climate variable were then derived (as in Eqs. A2 and A5 in Appendix A1, respectively) for each sample size. It was observed that both the Sobol' indices began to converge when the sample size exceeded 5000, and this was therefore used as the LHS sample size for all the sensitivity experiments in this study. Based on this sample size, a total of 30000 Sobol' samples were compiled as required to estimate the first- and total-order indices (as detailed in Appendix A1), which correspond to 30000 climate perturbations to be used to test PET sensitivity.

To generate time series of perturbed climate data, the 30000 joint perturbations to the four climate variables obtained by LHS were treated as change factors, and applied to the time series of daily values of the corresponding historical data. Rather than using a single daily mean value of temperature and relative humidity, the two PET models used in this study require both the daily minimum and maximum values; therefore, each pair of temperature variables and relative humidity variables was considered jointly and thus perturbed by the same amount for each day. In addition, to ensure physical plausibility of the perturbations, the daily maximum and minimum values of relative humidity were capped at a maximum of $100 \%$.
Table 2. Plausible perturbation bounds for each climate variable relative to their current levels.

\begin{tabular}{ll}
\hline $\begin{array}{l}\text { Climate } \\
\text { variable }\end{array}$ & $\begin{array}{l}\text { Perturbation } \\
\text { range }\end{array}$ \\
\hline$T$ & 0 to $+8^{\circ} \mathrm{C}$ \\
$\mathrm{RH}$ & -10 to $+10 \%$ \\
$R_{\mathrm{S}}$ & -10 to $+10 \%$ \\
$u_{z}$ & -20 to $+20 \%$ \\
\hline
\end{tabular}

Note: $T$ is daily temperature, $\mathrm{RH}$ is daily relative humidity, $R_{\mathrm{S}}$ is daily incoming solar radiation, $u_{z}$ is daily wind speed.

\subsection{Estimating PET responses to climate perturbation}

To represent the responses in PET as a result of the climate perturbations, we used both the Penman-Monteith and Priestley-Taylor models, which provide contrasting process representations to estimate PET. The Penman-Monteith model is often referred to as a combinational model, as it combines the energy balance and mass transfer components of ET, and takes into account vegetation-dependent processes such as aerodynamic and surface resistances (Eqs. A6 in Appendix A1). The model requires input of six climate variables, namely, $T_{\max }, T_{\min }, \mathrm{RH}_{\max }, \mathrm{RH}_{\min }, R_{\mathrm{S}}$ and $u_{z}$. The Priestley-Taylor model consists of a simpler structure, considering only the energy balance, without consideration of mass transfer or any impact from vegetation (Eq. A23 in Appendix A3). Therefore, the Priestley-Taylor model is also referred to as a radiation-based model. The model only requires five climate variables, including $T_{\max }, T_{\min }, \mathrm{RH}_{\max }, \mathrm{RH}_{\min }$ and $R_{\mathrm{s}}$.

To minimize the potential confounding effects of differences in vegetated surface, the evaporative surface was assumed to be the reference crop for all study sites; therefore, it was possible to use the FAO-56 version of the Penman-Monteith model (Allen et al., 1998). The detailed formulations of the two PET models, as well as the relevant constants and assumptions, are included in McMahon et al. (2013). Both models were implemented using the R package Evapotranspiration (http://cran.r-project.org/ web/packages/Evapotranspiration/index.html) (Guo et al., 2016b). From each model, two sets of estimated PET were obtained: (i) a single set of baseline (historical) PET data at each study site with the historical climate data and (ii) 30000 sets of perturbed PET data at each study site corresponding to the 30000 sets of perturbed climate data obtained using LHS, as detailed in Sect. 3.2.

\subsection{Analyses of PET sensitivity}

To assess the overall sensitivity of PET to plausible climate change, we first estimated the annual average percentage changes in PET (relative to the baseline PET) using all 
climate perturbations at the 30 study sites, with estimates from both the Penmen-Monteith and Priestley-Taylor models. A closer investigation of how PET sensitivity varies with baseline climate was conducted by plotting the ranges of all monthly PET responses against the average levels of each climate variable, for all study sites and all months. The reason for the choice of monthly timescale is that for some study sites, the climate can vary substantially by season; therefore, an annual analysis might obscure important sub-annual effects. To assess the relative importance of each climate variable for PET estimation from each model, we first compared the ranges of the two sets of PET changes, namely,

1. the range of all potential changes in PET obtained from the entire 30000 sets of climate perturbations from LHS; and

2. the conditional ranges of potential changes in PET assuming no change in one of the climate variables. This was obtained with using a subset of all climate perturbations used in (1), for which the changes in the specific conditioning climate variable were close to zero (within $\pm 0.1{ }^{\circ} \mathrm{C}$ for $T$, and within $\pm 0.1 \%$ for the other three variables).

In this way any difference between (1) and (2) was purely contributed by the impact of changing the specific conditioning climate variable. To quantify and compare the relative importance of each climate variable, we then utilized the Sobol' method, which was implemented within the $\mathrm{R}$ package sensitivity (https://cran.r-project.org/web/packages/ sensitivity/index.html). We estimated the Sobol' first-order sensitivity indices (as in Eq. A2, Appendix A1) to assess the role of each individual climate variable for each PET model, at the 30 study sites. The sum of all interaction effects was also calculated for each location as the difference between the sum of all first-order indices and one (Eq. A6, Appendix A1). The Sobol' first-order indices were then plotted against the baseline levels of each climate variable at the 30 study sites, to assess how the relative importance changes with the baseline climatic conditions.

\section{Results and discussion}

\subsection{Ranges of potential changes in PET in response to potential climate change for different climate zones}

We start by assessing the potential changes in PET in response to the full set of climate perturbations at the 30 study sites at the annual timescale, using both the PenmanMonteith and Priestley-Taylor models. The results are presented in Table 3 in terms of the minimum, maximum and average changes of PET relative to the 1995-2004 baseline, in response to the 30000 sets of climate perturbation at each study site. The two models suggest similar average PET changes at most locations, with the average changes obtained from the Penman-Monteith model across all the locations $(+13.38 \%)$ being slightly higher than that for the PriestleyTaylor model $(+10.91 \%)$. Greater differences between the two models were observed when considering the ranges of changes. In particular, the minimum and maximum values (averaged across all the 30 sites) were -13.66 and $+47.09 \%$ for the Penman-Monteith model, respectively, compared to -7.39 and $+34.47 \%$ for the Priestley-Taylor model. This corresponds to a range for the Penman-Monteith model being approximately $45 \%$ wider than that of the PriestleyTaylor model.

For each PET model, the magnitudes of average potential changes in PET display substantial variation across the locations, with both models suggesting the lowest average changes at arid locations and the highest average changes at humid locations, as was also observed in Table 3. Specifically, the Penman-Monteith model identified the highest average PET change at Flinders Island $(+17.15 \%)$, with the lowest average change at Alice Springs $(+9.80 \%)$. The Priestley-Taylor model identified the highest average change at Hobart $(+17.77 \%)$, with the lowest at Tennant Creek $(+7.09 \%)$.

To further investigate how potential change in PET varies with different climatic conditions, we now focus on the associations between the PET responses and the baseline levels of the four climate variables for each month of the year and across the 30 study sites. Starting with the PenmanMonteith model (Fig. 3), it is clear that the PET response displays a clear association with the baseline levels of climate variables, with higher magnitude of responses for locations that are cooler (low $T$ ), more humid (high $\mathrm{RH}$ ), and receiving less solar radiation (low $R_{\mathrm{S}}$ ). The highest associations can be found with $T$ (Fig. 3a), with the monthly changes in PET ranging from -30.2 to $+98.3 \%$ for the lowest baseline $T$ value of $5.0^{\circ} \mathrm{C}$, compared to a range of -13.3 to $+46.6 \%$ for the highest baseline $T$ of $30.3^{\circ} \mathrm{C}$. Similarly, the range of Penman-Monteith PET responses also shows clear decreases with baseline $R_{\mathrm{S}}$ (Fig. 3c), and increases with baseline RH (Fig. 3b). The baseline $u_{z}$ (Fig. 3d) levels show no obvious impact on the PET responses.

The potential responses in PET obtained from PriestleyTaylor was also investigated (Fig. 4), and results are consistent with the results from the Penman-Monteith model, although the overall ranges of responses were smaller for each variable as anticipated from the results in Table 3. Interestingly, regardless of the choice of PET model, the range of PET responses at the monthly scale is larger than the range for the annual scale suggesting greater uncertainty at higher temporal resolutions.

In addition to assessing the impact of baseline climatic conditions, we are also interested in the role of baseline hydrological conditions (represented by the PET / $P$ ratio at each study site) on the potential responses in PET. Since the hydrological conditions can vary substantially over the course of a year for each study site, for this analysis we 

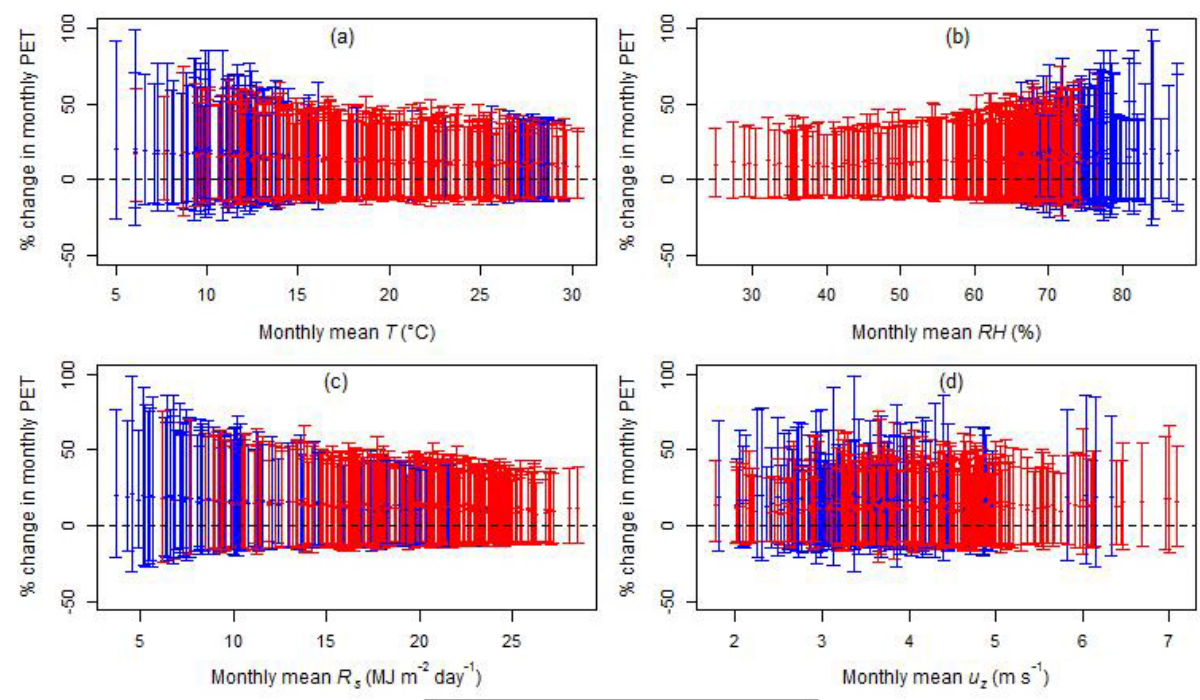

- Energy-limited — Water-limited

Figure 3. Ranges of monthly PET responses obtained from the Penman-Monteith model, plotted against the monthly baseline levels of (a) temperature, (b) relative humidity, (c) solar radiation and (d) wind speed at 30 study sites. Each vertical line represents the range of all potential changes in PET in response to the full set of climate perturbations for a single month at a single location, with the mean represented by the point on the line. The classification of energy- and water-limited months is based on the corresponding monthly PET / $P$ ratios.
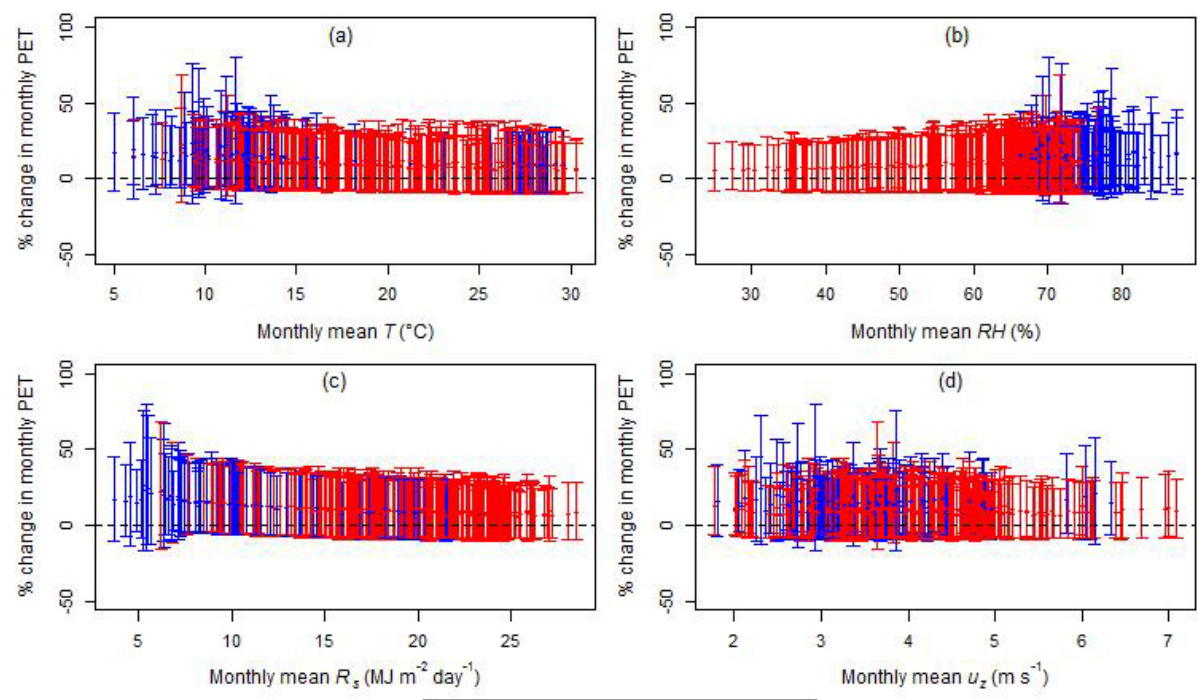

- Energy-limited — Water-limited

Figure 4. Range of monthly PET responses obtained from the Priestley-Taylor model, plotted against the monthly baseline levels of (a) temperature, (b) relative humidity, (c) solar radiation and (d) wind speed at 30 study sites. Each vertical line represents the range of all potential changes in PET in response to the full set of climate perturbations for a single month at a single location, with the mean represented by the point on the line. The classification of energy- and water-limited months is based on the corresponding monthly PET / $P$ ratios.

focused on the PET / $P$ ratios estimated on a monthly basis, and thus differ from the long-term PET / $P$ ratios presented in Table 1. These results are also shown in Figs. 3 and 4 , with red-colored bars denoting water-limited conditions, and blue-colored bars denoting energy-limited conditions. These figures show that the magnitude of potential responses in PET is generally larger under energy-limited con- ditions, regardless of the choice of PET model. In contrast, for water-limited conditions, the potential responses in PET only vary within approximately half of the entire range obtained from each PET model. However, when exploring the association with temperature (Figs. 3a and 4a) in more detail, the magnitude of responses in PET is in fact the lowest for energy-limited conditions during warm months (i.e., when 
Table 3. Maximum, minimum and average of all possible changes in annual average PET in response to the full set of climate perturbations from the Penman-Monteith and Priestley-Taylor models at the 30 study sites (as \% changes to baseline PET relative to the 1995-2004 baseline). The maximum and minimum changes from each model across all locations are in bold.

\begin{tabular}{|c|c|c|c|c|c|c|c|}
\hline \multirow[t]{2}{*}{ No. } & \multirow[t]{2}{*}{ Study site name } & \multicolumn{3}{|c|}{ Penman-Monteith } & \multicolumn{3}{|c|}{ Priestley-Taylor } \\
\hline & & Min. & Max. & Avg. & Min. & Max. & Avg. \\
\hline 1 & Broome airport & -12.33 & 39.10 & 11.16 & -9.61 & 33.75 & 9.59 \\
\hline 2 & Perth & -13.20 & 46.67 & 13.52 & -7.98 & 34.17 & 10.62 \\
\hline 3 & Albany & -15.04 & 54.67 & 15.21 & -7.28 & 35.49 & 11.63 \\
\hline 4 & Giles & -12.30 & 37.57 & 10.68 & -7.73 & 25.83 & 7.27 \\
\hline 5 & Darwin & -12.73 & 39.10 & 10.92 & -9.82 & 33.84 & 9.50 \\
\hline 6 & Gove & -13.10 & 41.34 & 11.53 & -9.74 & 33.67 & 9.61 \\
\hline 7 & Tennant Creek & -12.28 & 36.45 & 10.21 & -8.35 & 26.31 & 7.09 \\
\hline 8 & Alice Springs & -10.88 & 34.00 & 9.80 & -8.00 & 27.41 & 7.92 \\
\hline 9 & Woomera & -12.84 & 43.48 & 12.73 & -7.48 & 30.35 & 9.18 \\
\hline 10 & Ceduna & -13.97 & 49.61 & 14.39 & -7.62 & 33.82 & 10.67 \\
\hline 11 & Adelaide airport & -14.47 & 49.80 & 14.17 & -7.22 & 34.55 & 11.09 \\
\hline 12 & Adelaide (kent town) & -13.10 & 45.43 & 13.17 & -7.15 & 33.70 & 10.78 \\
\hline 13 & Loxton & -12.55 & 44.05 & 12.96 & -7.18 & 33.34 & 10.67 \\
\hline 14 & Mount Gambier & -15.33 & 57.97 & 16.00 & -6.58 & 35.54 & 12.02 \\
\hline 15 & Weipa & -12.42 & 39.06 & 10.95 & -9.66 & 32.98 & 9.36 \\
\hline 16 & Cairns & -14.80 & 44.74 & 12.08 & -9.42 & 33.84 & 9.73 \\
\hline 17 & Townsville & -13.77 & 43.21 & 12.10 & -9.43 & 34.26 & 9.90 \\
\hline 18 & Cobar & -10.62 & 37.49 & 11.36 & -7.64 & 31.19 & 9.49 \\
\hline 19 & Williamtown & -13.64 & 47.99 & 13.68 & -7.66 & 34.11 & 10.76 \\
\hline 20 & Sydney & -16.24 & 53.71 & 14.46 & -7.61 & 35.24 & 10.98 \\
\hline 21 & Canberra & -12.41 & 46.17 & 13.85 & -6.95 & 33.24 & 10.92 \\
\hline 22 & Wagga Wagga & -13.00 & 46.34 & 13.43 & -7.09 & 33.27 & 10.74 \\
\hline 23 & Mildura & -12.61 & 44.50 & 13.05 & -7.24 & 32.75 & 10.38 \\
\hline 24 & East sale & -14.43 & 53.82 & 15.34 & -6.51 & 36.32 & 12.19 \\
\hline 25 & Scottsdale & -13.64 & 51.53 & 15.02 & -5.42 & 40.00 & 13.47 \\
\hline 26 & Bicheno & -14.81 & 52.11 & 14.87 & -4.91 & 46.38 & 15.68 \\
\hline 27 & Lake Leake & -16.06 & 60.36 & 16.45 & -5.11 & 36.03 & 12.84 \\
\hline 28 & Hobart & -15.97 & 56.29 & 15.78 & -4.57 & 50.36 & $\mathbf{1 7 . 7 7}$ \\
\hline 29 & Strathgordon village & -13.08 & 52.11 & 15.29 & -4.66 & 33.83 & 12.35 \\
\hline 30 & Flinders Island & -18.05 & 64.07 & 17.15 & -6.19 & 38.66 & 13.02 \\
\hline & Average & -13.66 & 47.09 & 13.38 & -7.39 & 34.47 & 10.91 \\
\hline
\end{tabular}

$T>25^{\circ} \mathrm{C}$, corresponding to the monsoonal summer months in the northern parts of Australia), and the highest for the energy-limited conditions during cool months (i.e., when $T<15^{\circ} \mathrm{C}$, corresponding to the wet winter months in southern Australia). This highlights the fact that it is the atmospheric temperature, rather than the level of aridity, which appears to affect the potential responses in PET. This finding leads to a different interpretation to previous studies, which indicated that the dominant drivers of spatially varying PET include aridity (Tabari and Hosseinzadeh Talaee, 2014) and wind speed (Gong et al., 2006).

The above results also have potential implications on likely AET changes in a future climate. In particular, the above analysis shows that cool and humid regions and seasons appear to show the greatest potential responses in PET, and given that water is not expected to be limited for these cases, the ratio between AET and PET is also likely to be the greatest for these cases. Therefore, one might expect a greater change to AET occurring at the locations and during times of the year where PET is most sensitive to changes in climate.

As a potential limitation to the above analysis, some reliability issues of the Penman-Monteith model have been discussed in a recent study by Milly and Dunne (2016), which suggested that the Penman-Monteith model may overestimate the potential changes in PET in these energy-limited regions relative to a GCM-based AET benchmark. They concluded that the potential changes in ET would be better described by GCMs than "off-line" PET models (such as the two models used in this study), as GCMs can explicitly consider more complex atmospheric processes, such as the interaction between $\mathrm{CO}_{2}$ and stomatal conductance. Nevertheless, it should be noted that the current reliability of GCMs in simulating ET is also questionable, due to the uncertainty in 

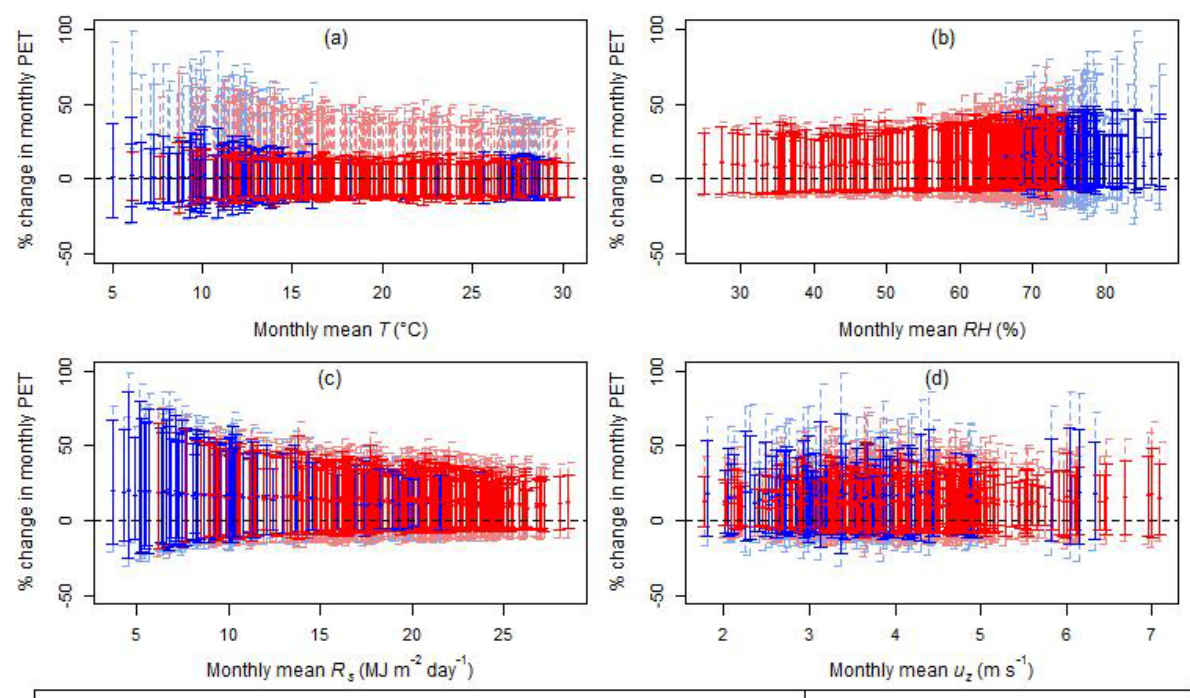

Conditional sensitivity (no change in each variable) -+- All sensitivity

- Energy-limited — Water-limited

Figure 5. Range of monthly PET responses from the Penman-Monteith model, plotted against the monthly baseline levels of (a) temperature, (b) relative humidity, (c) solar radiation and (d) wind speed at 30 study sites. Each dashed (solid) line represents the range of all potential changes in PET in response to the full set of climate perturbations (conditioned on no change in each climate variable) for a single month at a single location. The corresponding means are represented by the points on the lines. The classification of energy- and water-limited months is based on the corresponding monthly PET / $P$ ratios.

representing soil moisture and radiative energy at the evaporative surface (e.g., Seneviratne et al., 2013; Boé and Terray, 2008; Barella-Ortiz et al., 2013). In addition, due to the coarse scale of GCM output, downscaling is generally required to post-process output for use at local and regional scales, which often adds further bias and uncertainties to the GCM simulation and largely limits their applicability (e.g., Chen et al., 2012; Diaz-Nieto and Wilby, 2005). Therefore, although GCM results may be more suitable for largescale assessments, catchment-scale climate impact assessments are likely to be informed by "off-line" PET models for the foreseeable future. Consequently, the estimated potential changes in PET shown in this study will remain relevant for climate impact assessments conducted using these models.

\subsection{Relative importance of climate variables affecting PET for different climate zones}

We now explore the relative importance of each climate variable on overall PET sensitivity, by first visualizing the conditional responses of PET when holding each variable constant at its historical level while perturbing the remaining variables, and then comparing this to the unconditional estimates of all potential responses in PET (as shown in Figs. 3 and 4). Figure 5 shows the ranges of the monthly unconditional responses in PET (dashed lines) and the ranges of the monthly responses conditioned on zero change in each of $T$, $\mathrm{RH}, R_{\mathrm{S}}$ and $u_{z}$ (solid lines) for the Penman-Monteith model, plotted against the monthly baseline levels of the four climate variables at the 30 study sites.
The figure suggests that perturbations in $T$ have the greatest impact on the potential changes in PET compared to other climate variables (Fig. 5a), contributing to at least $45 \%$ of the entire range of PET responses compared to the unconditional results. Humidity also plays a significant role, although only for higher humidity levels (contributing up to $57 \%$ of the entire range of PET responses) with relatively minor influence for the less humid catchments (Fig. 5b). In contrast, the role of solar radiation (Fig. 5c) and wind (Fig. 5d) is generally minor, with the range of unconditional responses being only slightly wider than the range of conditional responses.

A similar analysis was conducted for the Priestley-Taylor model (Fig. 6), and shows somewhat different results compared to those obtained for the Penman-Monteith model. Consistent with Fig. 5a, temperature has the greatest impact, but in this case contributes up to $85 \%$ of the overall variability in PET responses (Fig. 6a). As a result, the range of PET changes contributed by the remaining variables (i.e., conditional responses with no change in temperature) is much smaller. Unlike in Fig. 5b, the role of relative humidity does not appear to increase significantly with increasing baseline humidity (Fig. 6b) and in general contributes less than $33 \%$ of the overall variability. The lower impact of RH on Priestley-Taylor PET compared to the impact on Penman-Monteith PET can be related to the structure of Priestley-Taylor model, which does not consider the aerodynamic processes; therefore, the impact of RH on PET through these processes is not accounted for (see Eqs. A13, A21 and A22 in Appendix A2). The role of solar radiation appears to be somewhat larger for high baseline solar radia- 

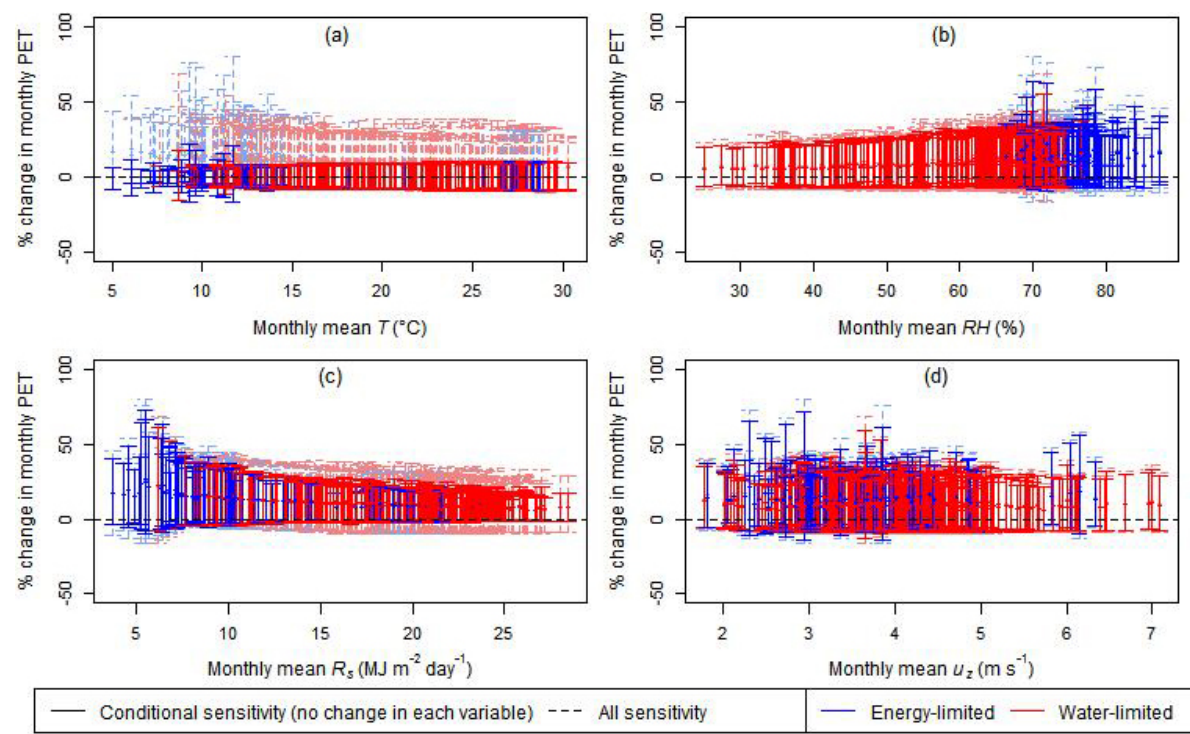

Figure 6. Range of monthly PET responses from the Priestley-Taylor model, plotted against the monthly baseline levels of (a) temperature, (b) relative humidity, (c) solar radiation and (d) wind speed at 30 study sites. Each dashed (solid) line represents the range of all potential change in PET in response to the full set of climate perturbations (conditioned on no change in each climate variable) for a single month at a single location. The corresponding means are represented by the points on the lines. The classification of energy- and water-limited months is based on the corresponding monthly PET / $P$ ratios.
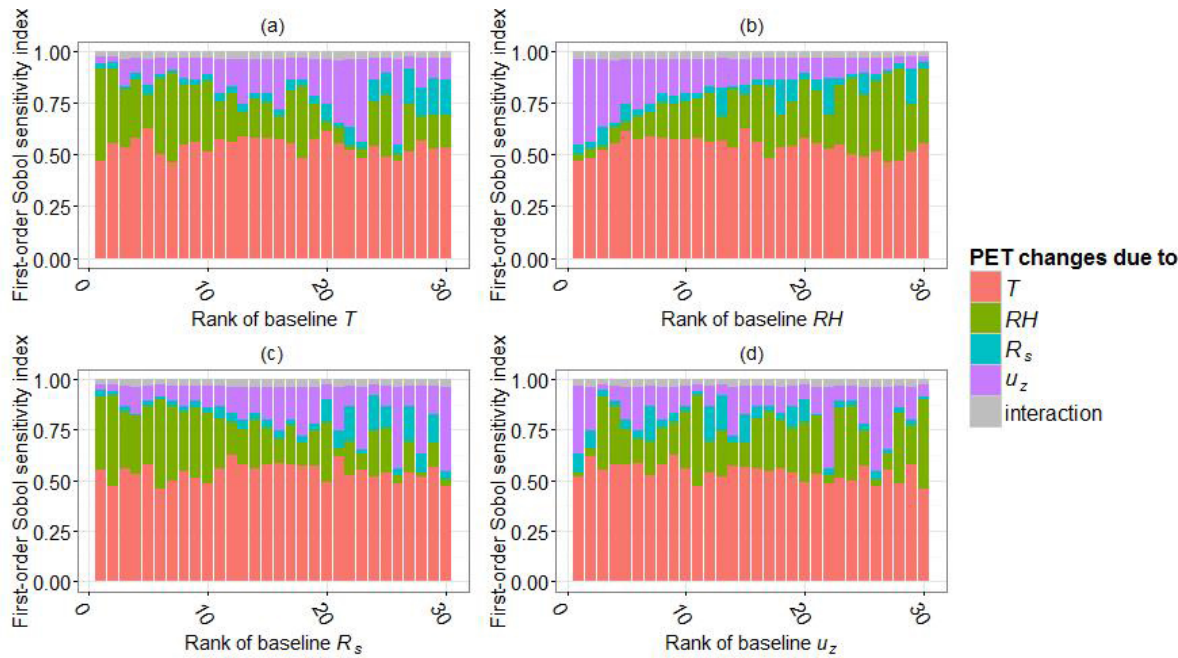

Figure 7. Sobol' first-order sensitivity indices of the Penman-Monteith model for changes in the four climate variables (colored) and their interaction effects (gray), plotted against the ranking of the average level of each climate variable at 30 study sites.

tion values (Fig. 6c) and wind is shown to have no impact as expected, since wind is not an input into the Priestley-Taylor model (Fig. 6d). However, it is worth noting that although the Priestley-Taylor model does not consider wind as an input variable, the range of unconditional responses of PET is slightly wider than the range of responses conditioned on no change in wind. This is because the conditional responses were estimated with only a subset of all climate perturbations (Sect. 3.4), which may not consist of the entire range of perturbation in each of the other three climate variables.
A more formal quantitative measure of the relative importance of each climate variable for PET is provided by the Sobol' indices. Figure 7 shows the Sobol' first-order indices of the Penman-Monteith PET to changes in the four climate variables at the annual scale, as well as their interactions. The first-order indices are plotted against the baseline levels of each climatic variable to observe the impact of baseline climate conditions. For presentation purposes, the baseline levels are represented by the rank of the baseline annual average value of each variable, rather than the absolute level of 

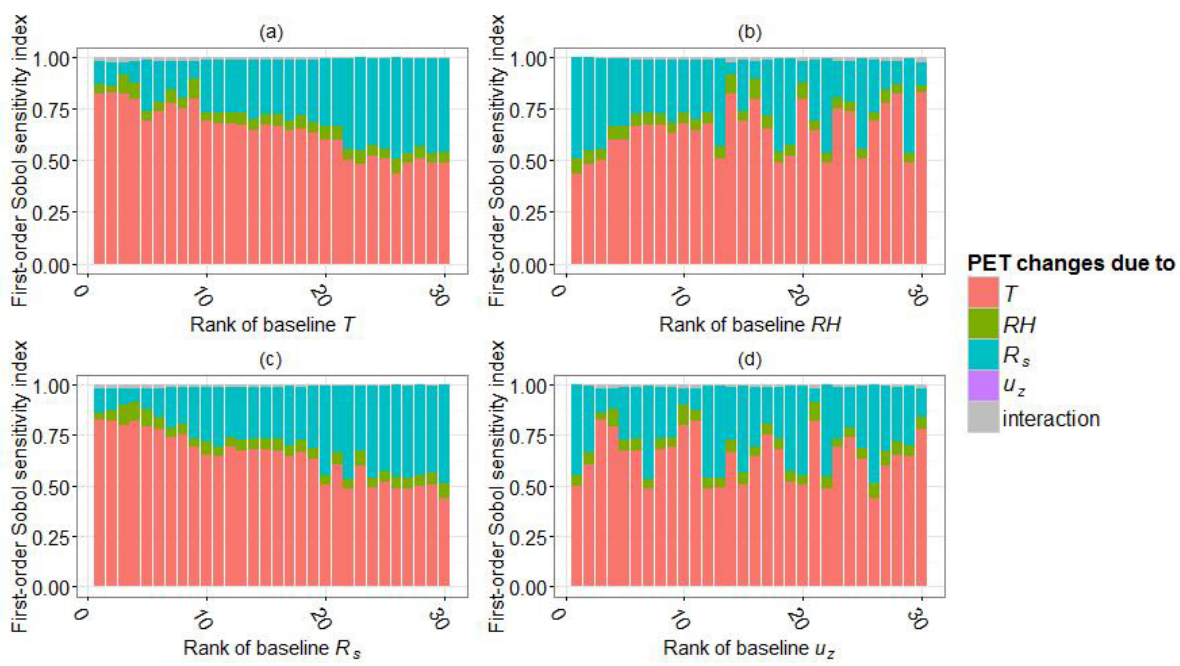

Figure 8. Sobol' first-order sensitivity indices of the Priestley-Taylor model for changes in the four climate variables (colored) and their interaction effects (gray), plotted against the ranking of the average level of each climate variable at 30 study sites.

each climate variable across the 30 study sites. The Sobol' indices in the figure show that $T$ is generally the most important variable for PET, with index values ranging from 0.46 to 0.62 . Since the Sobol' indices suggest the partitioning of the total variance of PET, these results are consistent with Fig. 5a, which suggests that perturbations in $T$ contribute to at least $45 \%$ of the variation in the estimated changes in PET. The role of wind and humidity in affecting the sensitivity values is also evident, with wind being the second-most important variable (with Sobol' indices up to 0.42 ) for sites with low baseline humidity, and humidity being the second-most important variable (with Sobol' indices up to 0.47) for sites that have high humidity (Fig. 7b). Solar radiation is generally the variable with the lowest Sobol' indices, where the largest contributions (up to $18 \%$ ) can be observed for warm catchments (Fig. 7a).

The Sobol' sensitivity indices are also presented for the Priestley-Taylor model (Fig. 8), and show substantial differences compared to those for the Penman-Monteith model. Temperature exhibits the largest sensitivity score in most cases, and ranges from 0.44 to 0.83 . The relative role of temperature varies most clearly as a function of both the baseline temperature (Fig. 8a) and the baseline solar radiation values (Fig. 8c), with temperature being particularly important for low temperature and low solar radiation sites. As temperature and radiation increase, the relative role of solar radiation becomes more important, reaching Sobol' index values of up to 0.49 . In contrast, the role of relative humidity is generally minor (with Sobol' indices within the range 0.03-0.1) and does not appear to vary as a function of baseline conditions. Finally, the role of wind is absent, given that this variable is not included as part of the Priestley-Taylor equation.

The differences between the Penman-Monteith and Priestley-Taylor models highlight the different physical as- sumptions underpinning the models, with aerodynamic processes being important for the Penman-Monteith model as indicated by the relative importance of $\mathrm{RH}$ and $u_{z}$ for this model, whereas $R_{\mathrm{S}}$ has a critical role in the Priestley-Taylor model, which is closely linked to the emphasis of radiative energy as the energy source for ET in the model.

Finally, comparing Figs. 7 and 8, it is apparent that the interactions among the four climate variables on PET (shown as gray bars) are greater in the Penman-Monteith model compared to the Priestley-Taylor model. Specifically, these interactions contribute fractions of $0.03-0.04$, and $0-0.02$ of the total variance in PET for the Penman-Monteith and Priestley-Taylor models, respectively. The relative magnitude of the interaction effects in the two models can be again related to their structural differences; the higher interaction effects in Penman-Monteith can be a result of the larger number of variables in this model compared with those in the Priestley-Taylor model.

It is difficult to assess the consistency of these sensitivity results with existing literature, given the different methodologies and data sets used in other studies. Although most PET sensitivity studies used only the Penman-Monteith PET model, there is still substantial discrepancy in results depending on the specific implementations of sensitivity analysis. For example, Gong et al. (2006) perturbed each of temperature, wind speed, relative humidity and solar radiation within $\pm 20 \%$ for the Changjiang basin in China, and observed that relative humidity was generally the most important variable driving PET, followed by solar radiation, temperature and wind speed. This contrasted with our results from the Penman-Monteith model, which showed temperature as the most important variable and solar radiation as the least important variable for almost all the stations analyzed, and may be attributable to the different baseline climates as 
well as the perturbation ranges used for the sensitivity analysis between the two studies.

The results of our study were more consistent with Goyal (2004), who concluded that PET is most sensitive to potential changes in temperature for an arid region in India, by applying a $\pm 20 \%$ perturbation on each of temperature, solar radiation, wind speed and vapor pressure. In contrast, Tabari and Hosseinzadeh Talaee (2014) also used a $\pm 20 \%$ perturbation range, but on only three climate variables, namely temperature, wind speed and sunshine hours, for several climate regions in Iran. Their study concluded that the catchment aridity was a major determinant of the sensitivity to temperature, wind speed and humidity, whereas our analysis highlights the importance of baseline temperature and humidity, rather than the aridity (or water- or energylimited status of the catchment) as a key driver.

PET sensitivity can further diversify by the choice of PET models, as illustrated in McKenney and Rosenberg (1993), in which the percentage changes in PET due to a $+6^{\circ} \mathrm{C}$ change can differ up to around $40 \%$, when estimated with eight alternative PET models. This lack of consistency in the relative importance of the climate variables for PET is not surprising given the findings of our study, as the results are strongly dependent on the design of the sensitivity analysis experiment, including the choice of study sites and study periods, the input climate variables considered, and the ways to perturb them (i.e., the choice of global or local perturbation and the ranges of perturbation in different input variables).

Nevertheless, the sensitivity results from this study suggest some distinct spatial patterns of the relative importance of different climate variables in Australia. Since the PenmanMonteith model is the most comprehensive physically based PET model, the above regionalization of the PET sensitivity from this model can be used as a benchmark to identify the key climate variables for estimating PET under potential climate change. This information can be particularly useful to suggest the potential suitability of specific PET models for regional applications. For example, since the PenmanMonteith PET showed higher sensitivity to wind at dry locations (Fig. 7b), it is expected that wind-dependent PET models (such as Penman and Penman-Monteith) would be more appropriate for predicting PET at these locations. In contrast, using simpler models that do not consider wind as an input (such as Priestley-Taylor) can be problematic for these locations. Although this study only examined two PET models, the results suggest that simpler empirical models are likely to ignore some potential dynamics and interactions within the climate variables, which makes them less preferred for PET estimation under changing climates.

Another particular issue in the selection of one or several PET models under a changing climate arises from considering the current reliability of available climate projections, as the models can show high levels of sensitivity to variables for which we currently do not have high-quality climate projections. For example, for a given emissions scenario, there is reasonable confidence in projections of temperature and relative humidity in Australia, but less confidence in projections of solar radiation and wind (Flato et al., 2013; CSIRO and Bureau of Meteorology, 2015). However, the radiation-based Priestley-Taylor model can show high sensitivity to solar radiation, particularly for warm locations with high baseline solar radiation (Fig. 8a and c), due to a particular emphasis on radiative energy and thus the empirical relationships between PET and solar radiation. Similarly, the PenmanMonteith model can exhibit higher sensitivity to wind for locations with low relative humidity (Fig. 7b). Therefore, the use of GCM projections at these locations may lead to significant uncertainty in PET estimates due to the uncertainty in the driving variables.

\section{Summary and conclusions}

In this study, we used a global sensitivity analysis to investigate the sensitivity of PET and the relative importance four climatic variables which influence PET $\left(T, \mathrm{RH}, R_{\mathrm{S}}\right.$ and $\left.u_{z}\right)$ under plausible future changes in these variables. The sensitivity analysis was conducted at 30 Australian case study locations within different climate zones to understand the impact of varying baseline hydro-climatic conditions. For the sensitivity analysis, the historical climate data at each study site were first perturbed to represent a large number of plausible climate change conditions, and then the responses in PET were estimated with both the Penman-Monteith and Priestley-Taylor models, from which the sensitivity of PET was analyzed. The key results are as follows:

- In general PET is most sensitive to potential changes in climate in regions with lower temperature, less solar radiation and greater humidity, where 2 -fold greater magnitude of changes in PET are expected compared to other locations in Australia.

- Within the plausible perturbations in $T, \mathrm{RH}, R_{\mathrm{S}}$ and $u_{z}$, PET is generally most sensitive to $T$. The relative importance of the other climate variables varies substantially with the PET models. $R_{\mathrm{S}}$ has a dominant role in the radiation-based Priestley-Taylor model, highlighting the importance of radiative energy in the model. In contrast, the importance of $\mathrm{RH}$ and $u_{z}$ are comparable for the Penman-Monteith model, whereas $R_{\mathrm{S}}$ has only little impact, reflecting the contribution of aerodynamic energy.

- The relative importance of climate variables in influencing PET depends very clearly on baseline climatic conditions. From Penman-Monteith, locations that are warmer, drier and receiving more solar radiation generally show greater sensitivity to $u_{z}$ and lower sensitivity to RH. For Priestley-Taylor, the importance of $T$ increases while that of $R_{\mathrm{S}}$ decreases for cooler locations and locations receiving less solar radiation. 
The global sensitivity analysis used in this study is a powerful tool for providing a comprehensive and consistent measure of PET sensitivity to different climatic variables, considering a wide range of possible changes in climate, across different models with different data requirements. However, we have identified space for improvements in further implementations. For example, the bounds of perturbation for each climate variable can have a substantial impact on PET sensitivity, and thus their selection requires careful justification (for example see Whateley et al., 2014; Shin et al., 2013). Therefore, alternative lines of evidence on possible changes in climate should be considered in setting these bounds: for example, the results of ensemble climate models (e.g., Collins et al., 2013), the impact of low-frequency climatic modes (e.g., Chen et al., 2013; Vincent et al., 2015), as well as findings from within paleoclimatology records (e.g., Ault et al., 2014; Ho et al., 2015).

The analysis in this study also lends itself to scenarioneutral analyses (Brown et al., 2012; Prudhomme et al., 2010), although the full implications on specific impacts of hydrological systems (flood risk, water supply, etc.) would require the sensitivity analysis to be propagated to runoff via explicitly modeling the interaction between ET and rainfallrunoff processes (e.g., Garcia and Tague, 2015; Roy et al., 2017). Furthermore, potential changes to precipitation, which were not analyzed here but that can have a significant impact on future runoff, would need to be considered. Within this context, the incorporation of alternative lines of evidence can therefore not only be used to define the bounds of the perturbations, but also can be superimposed onto the exposure space (e.g., as in Prudhomme et al., 2013a; Culley et al., 2016) to provide insight into the likelihood of possible changes. The outcomes of our study can feed into such a scenario-neutral analysis by providing guidance on the variables that are likely to be most important for a particular location, as well as providing insights on the potential implications of using alternative PET models on the overall sensitivity results.
Data availability. The temperature, relative humidity, wind speed, sunshine hours and rainfall data for the five case study locations were obtained from the Climate Data Online project website, http: //www.bom.gov.au/climate/data/ (Bureau of Meteorology, 2016). 
Appendix A: Sobol' sensitivity analysis and PET models

\section{A1 Sobol' sensitivity analysis (Sobol' et al., 2007)}

Sobol' is considered a variance-based method, which requires estimation of the total variance in a model output due to changes in its inputs is estimated with a Monte Carlo approach. To estimate the variances, a large number of samples is firstly drawn by varying all input variables simultaneously, and then a Sobol' sequence is constructed by re-sampling from within these Monte Carlo samples (Saltelli et al., 2010). According to Sobol' et al. (2007), to estimate the Sobol' firstorder and total-order indices with a Monte Carlo sample size of $n$ consisting of $p$ input variables, a Sobol' sequence with a total of $n \cdot(p+2)$ samples should be obtained, i.e., requiring $n \cdot(p+2)$ model evaluations.

Sobol' analysis partitions the total variance in model output to the contribution of each individual input variable (i.e., first-order effects), as well as their interactions (i.e., higher-order effects), as follows (equation adapted from Zhang et al., 2015):

$$
V_{Y}=\underbrace{\sum_{i=1}^{n} V_{i}}_{\text {Individual effects }}+\sum_{i<j} V_{i j}+\underbrace{\sum_{i<j<k} V_{i j k} \ldots+V_{1,2 \ldots, n} .}_{\text {interactions }}
$$

The outputs from Sobol' analysis include (equations adapted from Nossent et al., 2011)

1. first-order sensitivity index, which quantifies the individual contribution of each input variable to the total variance of the model's output:

$$
S_{i}=\frac{V_{i}}{V_{Y}}
$$

2. second- and higher-order sensitivity index, which quantifies the contribution of interactions among two or more input variables to the total variance of the model's output:

For second - order : $S_{i j}=\frac{V_{i j}}{V_{Y}}$,

For higher - order : $S_{i j \ldots n}=\frac{V_{i j \ldots n}}{V_{Y}}$;

3. total sensitivity index, which quantifies the total contribution of each input variable, including its individual effect as well as all its interactions with other input variables, to the total variance of the model's output:

$$
S_{T_{i}}=S_{i}+\sum_{j \neq i} S_{i j}=1-\frac{V_{\sim i}}{V_{Y}} .
$$

From Eqs. (A1) to (A4), the sum of individual effects of all input variables and all their interactions equals one (adapted from Zhang et al., 2015):

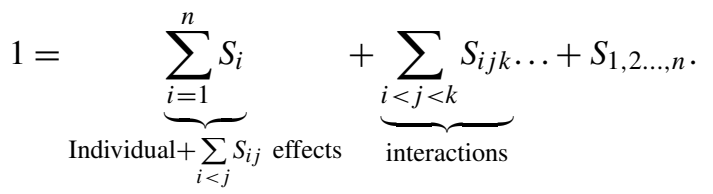

\section{A2 Penman-Monteith PET model (FAO-56) (as in McMahon et al., 2013)}

The Penman-Monteith PET model (FAO-56) is given as

$$
\mathrm{ET}=\frac{0.408 \Delta\left(R_{\mathrm{n}}-G\right)+\gamma \frac{900}{T_{\mathrm{a}}+273} u_{2}\left(v_{\mathrm{a}}^{*}-v_{\mathrm{a}}\right)}{\Delta+\gamma\left(1+0.34 u_{2}\right)} .
$$

The process for estimating each of the variables in this equation are described in the following sections.

\section{A2.1 Estimating $\Delta$ in Eq. (A7)}

$\Delta$ is the slope of vapor pressure curve in $\mathrm{kPa}^{\circ} \mathrm{C}^{-1}$, which is estimated by

$\Delta=\frac{4098\left[0.6108 \exp \left(\frac{17.27 \cdot T_{\mathrm{a}}}{T_{\mathrm{a}}+237.3}\right)\right]}{\left(T_{\mathrm{a}}+237.3\right)^{2}}$.

In Eq. (A8), $T_{\mathrm{a}}$ is the average daily temperature in ${ }^{\circ} \mathrm{C}$, calculated as

$T_{\mathrm{a}}=\frac{T_{\max }+T_{\min }}{2}$.

\section{A2.2 Estimating $\boldsymbol{R}_{\mathrm{n}}$ in Eq. (A7)}

$R_{\mathrm{n}}$ is the net incoming solar radiation at the evaporative surface in $\mathrm{MJ} \mathrm{m}^{-2} \mathrm{day}^{-1}$, which is estimated by

$R_{\mathrm{n}}=R_{\mathrm{ns}}-R_{\mathrm{nl}}$

In Eq. (A10), $R_{\mathrm{ns}}$ is the net shortwave solar radiation, estimated by

$R_{\mathrm{ns}}=(1-\alpha) R_{\mathrm{s}}$

In Eq. (A11), $\alpha$ is the albedo at evaporative surface which is fixed at 0.23 in this equation, and $R_{\mathrm{S}}$ is the measured or estimated incoming solar radiation in $\mathrm{MJ} \mathrm{m}^{-2} \mathrm{day}^{-1} . R_{\mathrm{nl}}$ is the net outgoing longwave radiation, estimated as

$$
\begin{aligned}
R_{\mathrm{nl}}= & \sigma\left(0.34-0.14 v_{\mathrm{a}}^{0.5}\right) \frac{\left(T_{\max }+237.2\right)^{4}+\left(T_{\min }+237.2\right)^{4}}{2} \\
& \left(1.35 \frac{R_{\mathrm{s}}}{R_{\mathrm{s}_{0}}}-0.35\right) .
\end{aligned}
$$

In Eq. (A12): $\sigma$ is Stefan-Boltzmann constant $=4.903 \times 10^{-9} \mathrm{MJ} \mathrm{m}^{-2} \mathrm{day}^{-1}{ }^{\circ} \mathrm{K}^{-4}, v_{\mathrm{a}}$ is the mean 
daily actual vapor pressure in kilopascals, $R_{\mathrm{s}_{0}}$ is the clearsky radiation in $\mathrm{MJ} \mathrm{m}^{-2}$ day $^{-1}$. $v_{\mathrm{a}}$ and $R_{\mathrm{S}_{0}}$ estimated by Eqs. (A13) and (A14), respectively:

$$
\begin{aligned}
& v_{\mathrm{a}}=\frac{v_{\mathrm{a}}^{*}\left(T_{\max }\right) \frac{\mathrm{RH}_{\max }}{100}+v_{\mathrm{a}}^{*}\left(T_{\min }\right) \frac{\mathrm{RH}_{\min }}{100}}{2}, \\
& R_{\mathrm{s}_{0}}=\left(0.75+2 \times 10^{-5} \mathrm{Elev}\right) R_{\mathrm{a}} .
\end{aligned}
$$

In Eq (A14), Elev is the ground elevation above sea level at the measurement location, and $R_{\mathrm{a}}$ is the extraterrestrial solar radiation in $\mathrm{MJ} \mathrm{m}^{-2}$ day $^{-1}$, estimated as

$$
\begin{aligned}
R_{\mathrm{a}} & =\frac{1440}{\pi} G_{\mathrm{sc}} d_{\mathrm{r}}^{2}\left(\omega_{\mathrm{s}} \sin (\text { lat }) \sin (\delta)\right. \\
& \left.+\cos (\text { lat }) \sin (\text { lat }) \sin \left(\omega_{\mathrm{s}}\right)\right) .
\end{aligned}
$$

In Eq. (A15), $G_{\mathrm{sc}}$ is the solar constant $=0.0820 \mathrm{MJ} \mathrm{m}^{-2} \mathrm{~min}^{-1}$, lat is the latitude in radiance, $d_{\mathrm{r}}$ is the inverse relative distance between Earth and Sun, $\delta$ is the solar declination in radians and $\omega_{\mathrm{s}}$ is the sunset hour angle in radians. The $d_{\mathrm{r}}, \delta$ and $\omega_{\mathrm{s}}$ are estimated as follows:

$d_{\mathrm{r}}^{2}=1+0.033 \cos \left(\frac{2 \pi}{365} \mathrm{DoY}\right)$ with DoY as the day

$$
\text { of the year, }
$$

$\delta=0.409 \sin \left(\frac{2 \pi}{365} \operatorname{DoY}-1.39\right)$,

$\omega_{\mathrm{s}}=\operatorname{arcos}[-\tan ($ lat $) \tan (\delta)]$.

\section{A2.3 Estimating other variables in Eq. (A7)}

- $G$ is negligible for daily time step.

$-\gamma$ is the psychrometric constant in $\mathrm{kPa}^{\circ} \mathrm{C}^{-1}$, estimated as

$\gamma=0.00163 \frac{P}{\lambda}$ where $P$ is the pressure

at elevation $z$ meters.

$u_{2}$ is the daily average wind speed measured at $2 \mathrm{~m}$ in $\mathrm{m} \mathrm{s}^{-1}$, which can be estimated from the measured wind speed at $z$ meters as

$u_{2}=u_{z} \frac{\ln \left(\frac{2}{z_{0}}\right)}{\ln \left(\frac{z}{z_{0}}\right)}$ where $z_{0}$ is the roughness

height in meters.

(A18) $\left(v_{\mathrm{a}}^{*}-v_{\mathrm{a}}\right)$ is the vapor pressure deficit in kilopascals, in which $v_{\mathrm{a}}$ is the mean daily actual vapor pressure in kilopascals, estimated as Eq. (A13); $v_{\mathrm{a}}^{*}$ is the daily saturation vapor pressure in kilopascals, estimated as

$$
v_{\mathrm{a}}^{*}=\frac{v_{\mathrm{a}}^{*}\left(T_{\max }\right)+v_{\mathrm{a}}^{*}\left(T_{\min }\right)}{2} .
$$

In Eq. (A21), $v_{\mathrm{a}}^{*}\left(T_{\max }\right)$ and $v_{\mathrm{a}}^{*}\left(T_{\min }\right)$ are the vapor pressures at temperatures $T_{\max }$ and $T_{\min }$ in ${ }^{\circ} \mathrm{C}$ are estimated with

$$
v_{T}^{*}=0.6108 \exp \left[\frac{17.27 T}{T+237.3}\right] \text {. }
$$

\section{A3 Priestley-Taylor PET model (as in McMahon et al., 2013)}

The Priestley-Taylor PET model is given as

$$
\mathrm{ET}=\alpha_{\mathrm{PT}} \cdot\left[\frac{\Delta}{\Delta+\gamma} \frac{R_{\mathrm{n}}}{\lambda}-\frac{G}{\lambda}\right]
$$

where

- $\alpha_{\mathrm{PT}}$ is the albedo specifically used for the PriestleyTaylor model, since an evaporative surface of reference crop was assumed, this has a value of 1.12 which was for a similar surface of short grass (see Table S8 of the Supplement of McMahon et al., 2013);

$-\Delta$ is the slope of vapor pressure curve in $\mathrm{kPa}^{\circ} \mathrm{C}^{-1}$, estimated as Eq. (A8);

$-\gamma$ is the psychrometric constant in $\mathrm{kPa}^{\circ} \mathrm{C}^{-1}$, estimated as Eq. (A18);

$-\lambda$ is the latent heat of vaporization, which is $2.45 \mathrm{MJ} \mathrm{kg}^{-1}$ at $20^{\circ} \mathrm{C}$;

- $R_{\mathrm{n}}$ is the net incoming solar radiation at the evaporative surface in $\mathrm{MJ} \mathrm{m}^{-2}$ day $^{-1}$, which is estimated in the same way as Eq. (A10);

- $G$ is negligible for daily time step. 
Competing interests. The authors declare that they have no conflict of interest.

Acknowledgements. The authors wish to thank Giovanni Ravazzani and four anonymous reviewer for their thoughtful comments on the manuscript.

Edited by: N. Romano

Reviewed by: G. Ravazzani and three anonymous referees

\section{References}

Akhtar, M., Ahmad, N., and Booij, M. J.: The impact of climate change on the water resources of Hindukush-KarakorumHimalaya region under different glacier coverage scenarios, J. Hydrol., 355, 148-163, doi:10.1016/j.jhydrol.2008.03.015, 2008.

Allen, R. G., Pereira, L. S., Raes, D., and Smith, M.: Crop evapotranspiration - Guidelines for computing crop water requirements, FAO Irrigation and drainage paper 56, FAO, Rome, 1998.

Arnell, N. W.: The effect of climate change on hydrological regimes in Europe: a continental perspective, Global Environ. Change, 9, 5-23, doi:10.1016/S0959-3780(98)00015-6, 1999.

Ault, T. R., Cole, J. E., Overpeck, J. T., Pederson, G. T., and Meko, D. M.: Assessing the Risk of Persistent Drought Using Climate Model Simulations and Paleoclimate Data, J. Climate, 27, 75297549, doi:10.1175/JCLI-D-12-00282.1, 2014.

Barella-Ortiz, A., Polcher, J., Tuzet, A., and Laval, K.: Potential evaporation estimation through an unstressed surface-energy balance and its sensitivity to climate change, Hydrol. Earth Syst. Sci., 17, 4625-4639, doi:10.5194/hess-17-4625-2013, 2013.

Bell, V. A., Kay, A. L., Davies, H. N., and Jones, R. G.: An assessment of the possible impacts of climate change on snow and peak river flows across Britain, Climatic Change, 136, 539-553, doi:10.1007/s10584-016-1637-x, 2016.

Boé, J. and Terray, L.: Uncertainties in summer evapotranspiration changes over Europe and implications for regional climate change, Geophys. Res. Lett., 35, L05702, doi:10.1029/2007GL032417, 2008.

Brown, C., Ghile, Y., Laverty, M., and Li, K.: Decision scaling: Linking bottom-up vulnerability analysis with climate projections in the water sector, Water Resour. Res., 48, W09537, doi:10.1029/2011WR011212, 2012.

Bureau of Meteorology: Climate Data Online, available at: http:// www.bom.gov.au/climate/data/ (last access: April 2017), 2016.

Chang, S., Graham, W. D., Hwang, S., and Muñoz-Carpena, R.: Sensitivity of future continental United States water deficit projections to general circulation models, the evapotranspiration estimation method, and the greenhouse gas emission scenario, Hydrol. Earth Syst. Sci., 20, 3245-3261, doi:10.5194/hess-20-32452016, 2016.

Chen, H., Xu, C.-Y., and Guo, S.: Comparison and evaluation of multiple GCMs, statistical downscaling and hydrological models in the study of climate change impacts on runoff, J. Hydrol., 434435, 36-45, doi:10.1016/j.jhydrol.2012.02.040, 2012.

Chen, W., Lan, X., Wang, L., and Ma, Y.: The combined effects of the ENSO and the Arctic Oscillation on the winter climate anomalies in East Asia, Chinese Sci. Bull., 58, 1355-1362, doi:10.1007/s11434-012-5654-5, 2013.

Chiew, F. H. S., Teng, J., Vaze, J., Post, D. A., Perraud, J. M., Kirono, D. G. C., and Viney, N. R.: Estimating climate change impact on runoff across southeast Australia: Method, results, and implications of the modeling method, Water Resour. Res., 45, W10414, doi:10.1029/2008WR007338, 2009.

Collins, M., Knutti, R., Arblaster, J., Dufresne, J.-L., Fichefet, T., Friedlingstein, P., Gao, X., Gutowski, W. J., Johns, T., Krinner, G., Shongwe, M., Tebaldi, C., Weaver, A. J., and Wehner, M.: Long-term Climate Change: Projections, Commitments and Irreversibility, in: Climate Change 2013: The Physical Science Basis, Contribution of Working Group I to the Fifth Assessment Report of the Intergovernmental Panel on Climate Change, edited by: Stocker, T. F., Qin, D., Plattner, G.-K., Tignor, M., Allen, S. K., Boschung, J., Nauels, A., Xia, Y., Bex, V., and Midgley, P. M., Cambridge University Press, Cambridge, UK and New York, NY, USA, 1029-1136, 2013.

CSIRO and Bureau of Meteorology: Climate Change in Australia Information for Australia's Natural Resource Management Regions, Technical Report, CSIRO and Bureau of Meteorology, Australia, 2015.

Culley, S., Noble, S., Yates, A., Timbs, M., Westra, S., Maier, H. R., Giuliani, M., and Castelletti, A.: A bottom-up approach to identifying the maximum operational adaptive capacity of water resource systems to a changing climate, Water Resour. Res., 52, 6751-6768, doi:10.1002/2015WR018253, 2016.

Diaz-Nieto, J. and Wilby, R. L.: A comparison of statistical downscaling and climate change factor methods: impacts on low flows in the River Thames, United Kingdom, Climatic Change, 69, 245-268, 2005.

Dingman, S. L.: Physical Hydrology, 3rd Edn., Waveland Press, Long Grove, Illinois, USA, 2015.

Donohue, R. J., McVicar, T. R., and Roderick, M. L.: Generating Australian potential evaporation data suitable for assessing the dynamics in evaporative demand within a changing climate, CSIRO, Water for a Healthy Country National Research Flagship, 50 pp., 2009.

Donohue, R. J., McVicar, T. R., and Roderick, M. L.: Can dynamic vegetation information improve the accuracy of Budyko's hydrological model?, J. Hydrol., 390, 23-34, 2010.

Ekström, M., Jones, P. D., Fowler, H. J., Lenderink, G., Buishand, T. A., and Conway, D.: Regional climate model data used within the SWURVE project - 1: projected changes in seasonal patterns and estimation of PET, Hydrol. Earth Syst. Sci., 11, 1069-1083, doi:10.5194/hess-11-1069-2007, 2007.

Felix, T. P., Petra, D., Stephanie, E., and Martina, F.: Impact of climate change on renewable groundwater resources: assessing the benefits of avoided greenhouse gas emissions using selected CMIP5 climate projections, Environ. Res. Lett., 8, 024023, doi:10.1088/1748-9326/8/2/024023, 2013.

Flato, G., Marotzke, J., Abiodun, B., Braconnot, P., Chou, S. C., Collins, W., Cox, P., Driouech, F., Emori, S., and Eyring, V.: Evaluation of climate models, in: Climate Change 2013: The Physical Science Basis, Contribution of Working Group I to the Fifth Assessment Report of the Intergovernmental Panel on Climate Change, Cambridge University Press, Cambridge, 741866, 2013. 
Garcia, E. S. and Tague, C. L.: Subsurface storage capacity influences climate-evapotranspiration interactions in three western United States catchments, Hydrol. Earth Syst. Sci., 19, 48454858, doi:10.5194/hess-19-4845-2015, 2015.

Gerrits, A., Savenije, H., Veling, E., and Pfister, L.: Analytical derivation of the Budyko curve based on rainfall characteristics and a simple evaporation model, Water Resour. Res., 45, W04403, doi:10.1029/2008WR007308, 2009.

Gong, L., Xu, C.-Y., Chen, D., Halldin, S., and Chen, Y. D.: Sensitivity of the Penman-Monteith reference evapotranspiration to key climatic variables in the Changjiang (Yangtze River) basin, J. Hydrol., 329, 620-629, doi:10.1016/j.jhydrol.2006.03.027, 2006.

Gosling, S. N., Taylor, R. G., Arnell, N. W., and Todd, M. C.: A comparative analysis of projected impacts of climate change on river runoff from global and catchment-scale hydrological models, Hydrol. Earth Syst. Sci., 15, 279-294, ' doi:10.5194/hess15-279-2011, 2011.

Goyal, R. K.: Sensitivity of evapotranspiration to global warming: a case study of arid zone of Rajasthan (India), Agr. Water Manage., 69, 1-11, doi:10.1016/j.agwat.2004.03.014, 2004.

Guillevic, P., Koster, R. D., Suarez, M. J., Bounoua, L., Collatz, G. J., Los, S. O., and Mahanama, S. P. P.: Influence of the Interannual Variability of Vegetation on the Surface Energy Balance - A Global Sensitivity Study, J. Hydrometeorol., 3, 617-629, doi:10.1175/1525-7541(2002)003<0617:IOTIVO>2.0.CO;2, 2002.

Guo, D., Westra, S., and Maier, H. R.: An inverse approach to perturb historical rainfall data for scenario-neutral climate impact studies, J. Hydrol., doi:10.1016/j.jhydrol.2016.03.025, in press, 2016a.

Guo, D., Westra, S., and Maier, H. R.: An R package for modelling actual, potential and reference evapotranspiration, Environ. Model. Softw., 78, 216-224, doi:10.1016/j.envsoft.2015.12.019, 2016b.

Guo, D., Westra, S., and Maier, H. R.: Impact of evapotranspiration process representation on runoff projections from conceptual rainfall-runoff models, Water Resour. Res., 53, 435-454, doi:10.1002/2016WR019627, 2017.

Harrigan, S. and Berghuijs, W.: The Mystery of Evaporation, Streams of Thought (Young Hydrologic Society), doi:10.5281/zenodo.57847, 2016.

Ho, M., Kiem, A. S., and Verdon-Kidd, D. C.: A paleoclimate rainfall reconstruction in the Murray-Darling Basin (MDB), Australia: 1. Evaluation of different paleoclimate archives, rainfall networks, and reconstruction techniques, Water Resour. Res., 51, 8362-8379, doi:10.1002/2015WR017058, 2015.

Johnson, F. and Sharma, A.: Measurement of GCM skill in predicting variables relevant for hydroclimatological assessments, J. Climate, 22, 4373-4382, 2009.

Kay, A. L. and Davies, H. N.: Calculating potential evaporation from climate model data: A source of uncertainty for hydrological climate change impacts, J. Hydrol., 358, 221-239, doi:10.1016/j.jhydrol.2008.06.005, 2008.

Kay, A. L., Davies, H. N., Bell, V. A., and Jones, R. G.: Comparison of uncertainty sources for climate change impacts: flood frequency in England, Climatic Change, 92, 41-63, doi:10.1007/s10584-008-9471-4, 2009.
Kay, A. L., Crooks, S. M., and Reynard, N. S.: Using response surfaces to estimate impacts of climate change on flood peaks: assessment of uncertainty, Hydrol. Process., 28, 5273-5287, doi:10.1002/hyp.10000, 2014.

Koedyk, L. P. and Kingston, D. G.: Potential evapotranspiration method influence on climate change impacts on river flow: a mid-latitude case study, Hydrol. Res., 47, 951-963, doi:10.2166/nh.2016.152, 2016.

Köppen, W. P.: Grundriss der Klimakunde, W. de Gruyter, Berlin, Germany, 1931.

Köppen, W. P., Geiger, R., Borchardt, W., Wegener, K., Wagner, A., Knoch, K., Sapper, K., Ward, R. D., Brooks, C. F., and Connor, A.: Handbuch der klimatologie, 1, Gebrüder Borntraeger, Berlin, Germany, 1930.

Li, L., Maier, H. R., Partington, D., Lambert, M. F., and Simmons, C. T.: Performance assessment and improvement of recursive digital baseflow filters for catchments with different physical characteristics and hydrological inputs, Environ. Model. Softw., 54, 39-52, doi:10.1016/j.envsoft.2013.12.011, 2014.

Liu, M., Tian, H., Chen, G., Ren, W., Zhang, C., and Liu, J.: Effects of Land-Use and Land-Cover Change on Evapotranspiration and Water Yield in China During 1900-2001, J. Am. Water Resour. Assoc., 44, 1193-1207, doi:10.1111/j.1752-1688.2008.00243.x, 2008.

Lu, X., Bai, H., and Mu, X.: Explaining the evaporation paradox in Jiangxi Province of China: Spatial distribution and temporal trends in potential evapotranspiration of Jiangxi Province from 1961 to 2013, Int. Soil Water Conserv. Res., 4, 45-51, doi:10.1016/j.iswcr.2016.02.004, 2016.

McKenney, M. S. and Rosenberg, N. J.: Sensitivity of some potential evapotranspiration estimation methods to climate change, Agr. Forest Meteorol., 64, 81-110, doi:10.1016/01681923(93)90095-Y, 1993.

McMahon, T. A., Peel, M. C., Lowe, L., Srikanthan, R., and McVicar, T. R.: Estimating actual, potential, reference crop and pan evaporation using standard meteorological data: a pragmatic synthesis, Hydrol. Earth Syst. Sci., 17, 1331-1363, doi:10.5194/hess-17-1331-2013, 2013.

McVicar, T. R., Van Niel, T. G., Li, L. T., Roderick, M. L., Rayner, D. P., Ricciardulli, L., and Donohue, R. J.: Wind speed climatology and trends for Australia, 1975-2006: Capturing the stilling phenomenon and comparison with nearsurface reanalysis output, Geophys. Res. Lett., 35, L20403, doi:10.1029/2008GL035627, 2008.

McVicar, T. R., Donohue, R. J., O'Grady, A. P., and Li, L.: The effects of climatic changes on plant physiological and catchment ecohydrological processes in the high-rainfall catchments of the Murray-Darling Basin: A scoping study, prepared for the Murray-Darling Basin Authority (MDBA) by the Commonwealth Scientific and Industrial Research Organization (CSIRO) Water for a Healthy Country National Research Flagship, MDBA, Canberra, ACT, Australia, 2010.

McVicar, T. R., Roderick, M. L., Donohue, R. J., Li, L. T., Van Niel, T. G., Thomas, A., Grieser, J., Jhajharia, D., Himri, Y., Mahowald, N. M., Mescherskaya, A. V., Kruger, A. C., Rehman, S., and Dinpashoh, Y.: Global review and synthesis of trends in observed terrestrial near-surface wind speeds: Implications for evaporation, J. Hydrol., 416-417, 182-205, doi:10.1016/j.jhydrol.2011.10.024, 2012. 
Milly, P. C. D. and Dunne, K. A.: Potential evapotranspiration and continental drying, Nat.Clim. Change, 6, 946-949, doi:10.1038/nclimate3046, 2016.

Nossent, J., Elsen, P., and Bauwens, W.: Sobol'sensitivity analysis of a complex environmental model, Environ. Model. Softw., 26, 1515-1525, 2011.

Osidele, O. and Beck, M.: Identification of model structure for aquatic ecosystems usingregionalized sensitivity analysis, Water Sci. Technol., 43, 271-278, 2001.

Oudin, L., Hervieu, F., Michel, C., Perrin, C., Andréassian, V., Anctil, F., and Loumagne, C.: Which potential evapotranspiration input for a lumped rainfall-runoff model: Part 2 Towards a simple and efficient potential evapotranspiration model for rainfall-runoff modelling, J. Hydrol., 303, 290-306, doi:10.1016/j.jhydrol.2004.08.026, 2005.

Paton, F. L., Maier, H. R., and Dandy, G. C.: Relative magnitudes of sources of uncertainty in assessing climate change impacts on water supply security for the southern Adelaide water supply system, Water Resour. Res., 49, 1643-1667, doi:10.1002/wrcr.20153, 2013.

Paton, F. L., Maier, H. R., and Dandy, G. C.: Including adaptation and mitigation responses to climate change in a multiobjective evolutionary algorithm framework for urban water supply systems incorporating GHG emissions, Water Resour. Res., 50, 6285-6304, doi:10.1002/2013WR015195, 2014.

Prudhomme, C. and Williamson, J.: Derivation of RCM-driven potential evapotranspiration for hydrological climate change impact analysis in Great Britain: a comparison of methods and associated uncertainty in future projections, Hydrol. Earth Syst. Sci., 17, 1365-1377, doi:10.5194/hess-17-1365-2013, 2013.

Prudhomme, C., Wilby, R. L., Crooks, S., Kay, A. L., and Reynard, N. S.: Scenario-neutral approach to climate change impact studies: Application to flood risk, J. Hydrol., 390, 198-209, doi:10.1016/j.jhydrol.2010.06.043, 2010.

Prudhomme, C., Crooks, S., Kay, A., and Reynard, N.: Climate change and river flooding: part 1 classifying the sensitivity of British catchments, Climatic Change, 119, 933-948, doi:10.1007/s10584-013-0748-x, 2013a.

Prudhomme, C., Kay, A. L., Crooks, S., and Reynard, N.: Climate change and river flooding: Part 2 sensitivity characterisation for british catchments and example vulnerability assessments, Climatic Change, 119, 949-964, doi:10.1007/s10584-013-0726-3, $2013 b$

Prudhomme, C., Giuntoli, I., Robinson, E. L., Clark, D. B., Arnell, N. W., Dankers, R., Fekete, B. M., Franssen, W., Gerten, D., Gosling, S. N., Hagemann, S., Hannah, D. M., Kim, H., Masaki, Y., Satoh, Y., Stacke, T., Wada, Y., and Wisser, D.: Hydrological droughts in the 21st century, hotspots and uncertainties from a global multimodel ensemble experiment, P. Natl. Acad. Sci., 111, 3262-3267, doi:10.1073/pnas.1222473110, 2014.

Ravazzani, G., Ghilardi, M., Mendlik, T., Gobiet, A., Corbari, C., and Mancini, M.: Investigation of Climate Change Impact on Water Resources for an Alpine Basin in Northern Italy: Implications for Evapotranspiration Modeling Complexity, PLOS ONE, 9, e109053, doi:10.1371/journal.pone.0109053, 2014.

Roderick, M. L. and Farquhar, G. D.: The Cause of Decreased Pan Evaporation over the Past 50 Years, Science, 298, 1410-1411, doi:10.1126/science.1075390, 2002.
Roderick, M. L., Rotstayn, L. D., Farquhar, G. D., and Hobbins, M. T.: On the attribution of changing pan evaporation, Geophys Res. Lett., 34, L17403, doi:10.1029/2007GL031166, 2007.

Roy, T., Gupta, H. V., Serrat-Capdevila, A., and Valdes, J. B.: Using satellite-based evapotranspiration estimates to improve the structure of a simple conceptual rainfall-runoff model, Hydrol. Earth Syst. Sci., 21, 879-896, doi:10.5194/hess-21-879-2017, 2017.

Rustomji, P., Bennett, N., and Chiew, F.: Flood variability east of Australia's great dividing range, J. Hydrol., 374, 196-208, 2009.

Saltelli, A., Annoni, P., Azzini, I., Campolongo, F., Ratto, M., and Tarantola, S.: Variance based sensitivity analysis of model output. Design and estimator for the total sensitivity index, Compu. Phys. Commun., 181, 259-270, doi:10.1016/j.cpc.2009.09.018, 2010.

Seneviratne, S. I., Wilhelm, M., Stanelle, T., van den Hurk, B., Hagemann, S., Berg, A., Cheruy, F., Higgins, M. E., Meier, A., Brovkin, V., Claussen, M., Ducharne, A., Dufresne, J.-L., Findell, K. L., Ghattas, J., Lawrence, D. M., Malyshev, S., Rummukainen, M., and Smith, B.: Impact of soil moistureclimate feedbacks on CMIP5 projections: First results from the GLACE-CMIP5 experiment, Geophys. Res. Lett., 40, 52125217, doi:10.1002/grl.50956, 2013.

Shin, M.-J., Guillaume, J. H. A., Croke, B. F. W., and Jakeman, A. J.: Addressing ten questions about conceptual rainfall-runoff models with global sensitivity analyses in R, J. Hydrol., 503, 135-152, doi:10.1016/j.jhydrol.2013.08.047, 2013.

Sieber, A. and Uhlenbrook, S.: Sensitivity analyses of a distributed catchment model to verify the model structure, J. Hydrol., 310, 216-235, doi:10.1016/j.jhydrol.2005.01.004, 2005.

Sobol', I. M., Tarantola, S., Gatelli, D., Kucherenko, S. S., and Mauntz, W.: Estimating the approximation error when fixing unessential factors in global sensitivity analysis, Reliab. Eng. Syst. Saf., 92, 957-960, doi:10.1016/j.ress.2006.07.001, 2007.

Steinschneider, S. and Brown, C.: A semiparametric multivariate, multi-site weather generator with low-frequency variability for use in climate risk assessments, Water Resour. Res., 49, 72057220, doi:10.1002/wrcr.20528, 2013.

Stern, H., De Hoedt, G., and Ernst, J.: Objective classification of Australian climates, Aust. Meteorol. Mag., 49, 87-96, 2000.

Stocker, T. F., Qin, D., Plattner, G.-K., Tignor, M., Allen, S. K., Boschung, J., Nauels, A., Xia, Y., Bex, V., and Midgley, P. M.: Climate change 2013: The physical science basis, Intergovernmental Panel on Climate Change, in: Working Group I Contribution to the IPCC Fifth Assessment Report (AR5), Cambridge Univ Press, New York, 2013.

Tabari, H. and Hosseinzadeh Talaee, P.: Sensitivity of evapotranspiration to climatic change in different climates, Global Planet. Change, 115, 16-23, doi:10.1016/j.gloplacha.2014.01.006, 2014.

Tang, Y., Reed, P., van Werkhoven, K., and Wagener, T.: Advancing the identification and evaluation of distributed rainfall-runoff models using global sensitivity analysis, Water Resour. Res., 43, W06415, doi:10.1029/2006WR005813, 2007a.

Tang, Y., Reed, P., Wagener, T., and van Werkhoven, K.: Comparing sensitivity analysis methods to advance lumped watershed model identification and evaluation, Hydrol. Earth Syst. Sci., 11, 793817, doi:10.5194/hess-11-793-2007, 2007b.

Tang, Y., Reed, P., Wagener, T., and van Werkhoven, K.: Comparing sensitivity analysis methods to advance lumped watershed model 
identification and evaluation, Hydrol. Earth Syst. Sci., 11, 793817, doi:10.5194/hess-11-793-2007, 2007c.

Taylor, I. H., Burke, E., McColl, L., Falloon, P. D., Harris, G. R., and McNeall, D.: The impact of climate mitigation on projections of future drought, Hydrol. Earth Syst. Sci., 17, 2339-2358, doi:10.5194/hess-17-2339-2013, 2013.

van Griensven, A., Meixner, T., Grunwald, S., Bishop, T., Diluzio, M., and Srinivasan, R.: A global sensitivity analysis tool for the parameters of multi-variable catchment models, J. Hydrol., 324, 10-23, doi:10.1016/j.jhydrol.2005.09.008, 2006.

Vincent, L. A., Zhang, X., Brown, R. D., Feng, Y., Mekis, E., Milewska, E. J., Wan, H., and Wang, X. L.: Observed Trends in Canada's Climate and Influence of Low-Frequency Variability Modes, J. Climate, 28, 4545-4560, doi:10.1175/JCLI-D-1400697.1, 2015.
Whateley, S., Steinschneider, S., and Brown, C.: A climate change range-based method for estimating robustness for water resources supply, Water Resour. Res., 50, 8944-8961, 2014.

Wilby, R. L., Whitehead, P. G., Wade, A. J., Butterfield, D., Davis, R. J., and Watts, G.: Integrated modelling of climate change impacts on water resources and quality in a lowland catchment: River Kennet, UK, J. Hydrol., 330, 204-220, doi:10.1016/j.jhydrol.2006.04.033, 2006.

Zhang, X. Y., Trame, M. N., Lesko, L. J., and Schmidt, S.: Sobol Sensitivity Analysis: A Tool to Guide the Development and Evaluation of Systems Pharmacology Models, Pharmacometr. Syst. Pharmacol., 4, 69-79, doi:10.1002/psp4.6, 2015. 